\title{
REVIEW
}

\section{Global report on preterm birth and stillbirth (1 of 7): definitions, description of the burden and opportunities to improve data}

\author{
Joy E Lawn', Michael G Gravett², Toni M Nunes33, Craig E Rubens ${ }^{3,4}$, Cynthia Stanton*5 and the GAPPS Review Group
}

\begin{abstract}
Introduction: This is the first of seven articles from a preterm birth and stillbirth report. Presented here is an overview of the burden, an assessment of the quality of current estimates, review of trends, and recommendations to improve data.

Preterm birth: Few countries have reliable national preterm birth prevalence data. Globally, an estimated 13 million babies are born before 37 completed weeks of gestation annually. Rates are generally highest in low- and middleincome countries, and increasing in some middle- and high-income countries, particularly the Americas. Preterm birth is the leading direct cause of neonatal death (27\%); more than one million preterm newborns die annually. Preterm birth is also the dominant risk factor for neonatal mortality, particularly for deaths due to infections. Longterm impairment is an increasing issue.

Stillbirth: Stillbirths are currently not included in Millennium Development Goal tracking and remain invisible in global policies. For international comparisons, stillbirths include late fetal deaths weighing more than $1000 \mathrm{~g}$ or occurring after 28 weeks gestation. Only about $2 \%$ of all stillbirths are counted through vital registration and global estimates are based on household surveys or modelling. Two global estimation exercises reached a similar estimate of around three million annually; $99 \%$ occur in low- and middle-income countries. One million stillbirths occur during birth. Global stillbirth cause-of-death estimates are impeded by multiple, complex classification systems.

Recommendations to improve data: (1) increase the capture and quality of pregnancy outcome data through household surveys, the main data source for countries with 75\% of the global burden; (2) increase compliance with standard definitions of gestational age and stillbirth in routine data collection systems; (3) strengthen existing data collection mechanisms — especially vital registration and facility data — by instituting a standard death certificate for stillbirth and neonatal death linked to revised International Classification of Diseases coding; (4) validate a simple, standardized classification system for stillbirth cause-of-death; and (5) improve systems and tools to capture acute morbidity and long-term impairment outcomes following preterm birth.
\end{abstract}

Conclusion: Lack of adequate data hampers visibility, effective policies, and research. Immediate opportunities exist to improve data tracking and reduce the burden of preterm birth and stillbirth.

\section{Why focus on preterm birth and stillbirth?}

While under-5 mortality rates are improving in many countries worldwide, neonatal mortality rates (deaths in the first 28 days of life) have shown much less progress [1]. Neonatal deaths now account for more than $42 \%$ of

\footnotetext{
*Correspondence: cstanton@jhsph.edu
}

${ }^{5}$ Department of Population, Family and Reproductive Health, The Johns Hopkins

Bloomberg School of Public Health, Baltimore, Maryland, USA

Full list of author information is available at the end of the article under five deaths (Figure 1), up from 37\% in the year 2000 when the Millennium Development Goals (MDGs) were set [2,3]. MDG 4 targets a two-thirds reduction of under-five deaths between 1990 and 2015.

Complications of preterm birth are the leading direct cause of neonatal mortality, accounting for an estimated $27 \%$ of the almost four million neonatal deaths every year, and act as a risk factor for many neonatal deaths due to other causes, particularly infections [4]. Hence, achievement of MDG 4 is strongly influenced by progress in reducing neonatal deaths; and since preterm birth is the leading cause of these deaths, progress is dependent 


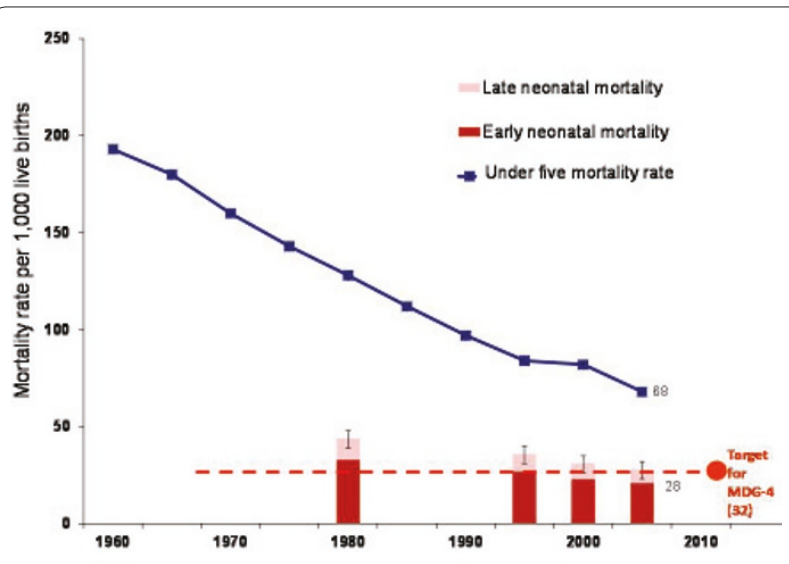

Figure 1. Early and late neonatal mortality rates and under 5 mortality rates per 1000, 1960-2007. Source: Lawn, Kerber et al. [1]; Data from UN databases updated to 2007.

on achieving high coverage of evidence-based interventions to prevent preterm delivery and to improve survival for preterm newborns [5]. In some high-income countries (HICs), preterm birth has been high on the maternal, newborn and child health $(\mathrm{MNCH})$ agenda for two decades, but is now starting to receive wider public health attention because of increasing preterm birth rates, particularly in the United States [6]. However, only recently has this issue started to reach the attention of higher-level policy makers in low- and middle-income countries (LMICs). Many countries, particularly in Latin America, have recognized the importance of preterm birth and are looking for solutions in prevention as well as improved care. Understanding and improving the current data are critical to setting priorities for action and for tracking progress.

Another adverse pregnancy outcome that is closely linked to preterm birth is stillbirth, which remains invisible on global policy agendas, as stillbirths are not included in MDG targets or tracking [7]. Each year there are an estimated 3.2 million stillbirths-almost as many as neonatal deaths. Attention to stillbirths has increased notably in the last few years. Important signs of change include the fact that estimation of disability-adjusted life years for stillbirth were calculated and included in the most recent edition of Disease Control Priorities for Developing Countries [8].

It is widely recognized that MDG 5 to improve maternal health has shown the least progress among all MDGs [9]. Maternal mortality is strongly correlated with stillbirth [10]. Increasing attention for preterm birth and stillbirth interventions, alongside increasing investment for mothers, will accelerate progress for these inextricable maternal, fetal, newborn and child health outcomes. Improved data on these pregnancy outcomes are crucial to guiding investment and tracking progress.
This is the first of seven articles in a global report on preterm birth and stillbirth. In this article we present estimates of the current burden, assess the quality of these estimates, review trends, and make recommendations to improve data. The second article discusses the process of pregnancy and childbirth, etiologies of preterm birth and stillbirth and opportunities through discovery science to identify pathways, and potential interventions [11]. Other articles discuss effectiveness of existing interventions [12], barriers and opportunities for scaling up interventions [13], advocacy [14], and ethical considerations [15]. The final article presents a Global Action Agenda created by about $200 \mathrm{MNCH}$ stakeholders [16].

\section{Preterm birth and stillbirth: assessing the status and quality of global estimates}

Less than $5 \%$ of the world's births occur in countries with complete vital registration or networks of representative, facility-based data. One-third of the world's births occur at home. Therefore, global-level data rely heavily on household surveys and modelled estimates. Global epidemiological estimation is a new science and builds on principles established for reviewing evidence for public health interventions-particularly with its focus on systematic literature reviews. However, approaches to standardizing the steps and assessing the quality of estimates are yet to be well-defined [17].

GRADE is a system designed to review the quality of evidence supporting health interventions [18]. Here, we have adapted the GRADE system to provide a summary assessment of the quality of major epidemiological parameters related to preterm birth and stillbirth, including rates, causes and impairment outcomes. The following two sub-sections, Preterm Birth and Stillbirth, start with a summary "Epidemiological GRADE" table (Table 1 and Table 5, respectively). They assess the input data and methods used to generate current global estimates for these parameters, current gaps and new work in progress.

\section{Preterm birth burden}

\section{Defining preterm birth}

The preterm birth rate is defined as the percentage of babies born before 37 completed weeks of gestation (Table 1). In addition, more granularity would be helpful for programs, such as dividing moderately preterm (33 to 36 completed weeks of gestation), very preterm ( $<32$ weeks) and extremely preterm ( $<28$ weeks). Particularly in countries where caesarean section is common, differentiating spontaneous and medically induced preterm birth is of programmatic relevance. Trend analysis in Canada suggests that a significant contribution to increasing preterm birth prevalence is related to more aggressive policies for caesarean section for poor fetal growth - which 


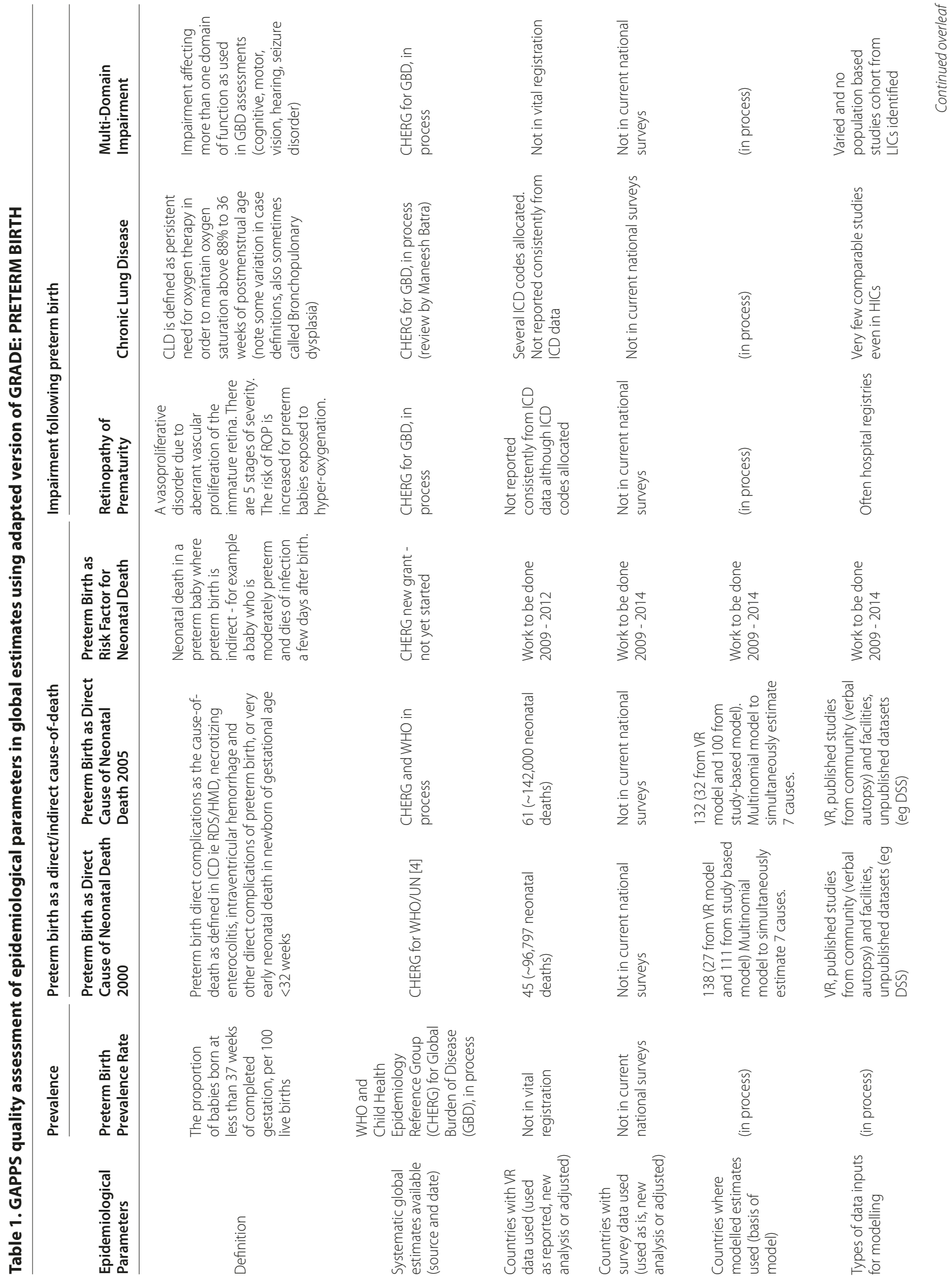




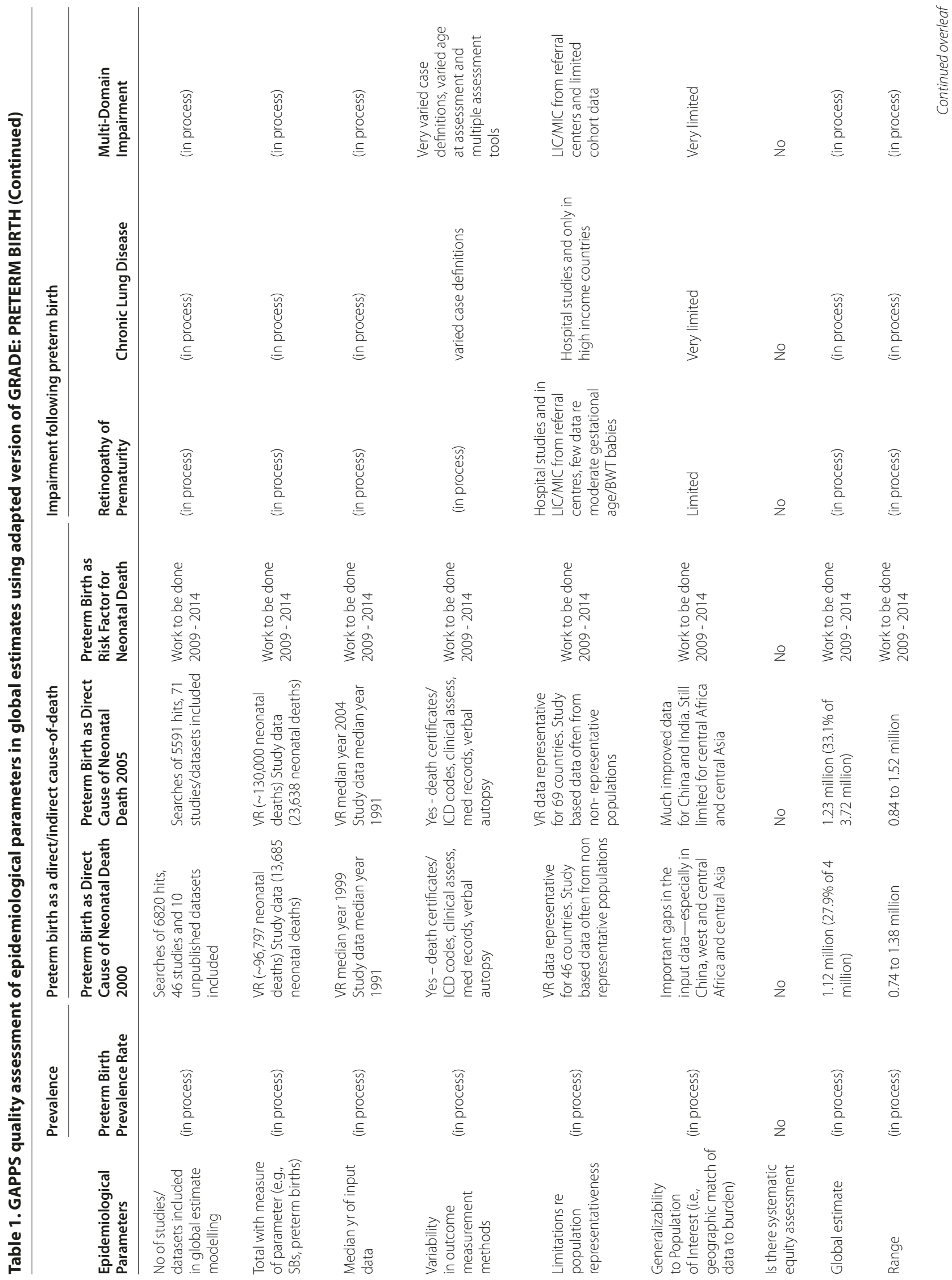



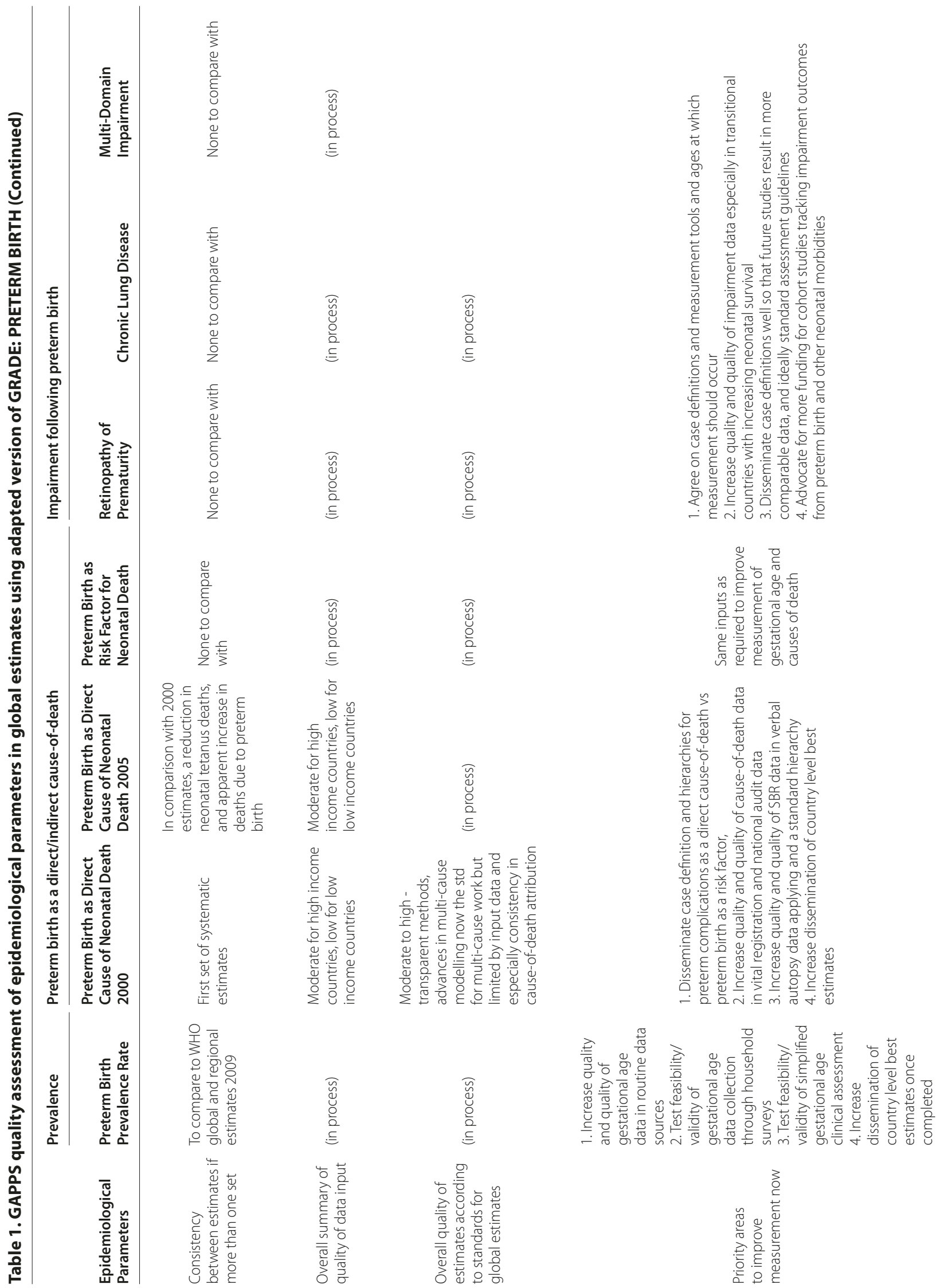
may reduce stillbirth but increase preterm birth [19, 20]. Although there is consensus on the broad definition, it is clear that preterm birth is a manifestation of a complex network of causal pathways. Consensus around the phenotypes and comparable case definitions are an important next step in better understanding this syndrome of preterm birth [11].

\section{Preterm birth prevalence rates}

A recent publication estimates about 13 million preterm babies are born each year worldwide [21]. However, country-level data are unavailable for most LMICs. Globally, around one-third of babies are born at home with little or no information on birthweight, gestational age or even survival. For those born in health care facilities, data on birthweight are often lacking or not recorded and compiled. Gestational age is rarely recorded and where recorded, tends to be based on self-reported last menstrual period (LMP), which is fairly imprecise. Differing methods such as LMP, clinical assessment, and ultrasound assessment have varying levels of accuracy. Despite the data gaps, estimates of the prevalence of low birth weight (LBW) are published each year in UNICEF's State of the World's Children report for most nations [22]. These estimates rely on available data in national household surveys, especially the Demographic and Health Survey (DHS) and UNICEF's Multiple Indicator Cluster Survey, applying adjustments for maternal reporting of the child's size and for heaping of birth weights on multiples of 500 grams [23]. Birth weight is only an indirect surrogate for gestational age, and many neonates - those either small or large for gestational age-will be incorrectly misclassified as preterm or term, respectively.

Preterm birth rates in the published literature range from $5 \%$ in HICs to $25 \%$ in LMICs $[24,25]$. Populationbased data for most LMICs are scarce, especially from Africa. The current status of the global data is summarized in Table 1. The lack of systematic country estimates for the prevalence of preterm birth is an important gap in the visibility of preterm birth. The WHO Special Programme of Research, Development and Research Training in Human Reproduction has recently published estimates of preterm prevalence at global and regional levels (Table 2) [21]. Rates are highest in least developed regions, especially Africa, but are also high in North America. A new exercise in partnership with the neonatal team at the Child Health Epidemiology Reference Group (CHERG) is a systematic review and modelling of preterm prevalence for WHO country-level estimates and that will also be used in the Global Burden of Disease (Table 1).

\section{Preterm birth rate disparities within countries}

Preterm birth rates vary greatly within countries and by sociodemographic characteristics. For example, in the
Table 2. Regional variation in the estimated preterm birth prevalence rates

\begin{tabular}{lccc}
\hline Region & $\begin{array}{c}\text { Preterm } \\
\text { births } \\
\mathbf{( x 1 0 0 0 )}\end{array}$ & $\begin{array}{c}\text { Preterm } \\
\text { birth } \\
\text { rate (\%) }\end{array}$ & $\begin{array}{c}\mathbf{9 5 \%} \\
\text { Confidence } \\
\text { Intervals }\end{array}$ \\
\hline World Total & 12,870 & 9.6 & $9.1-10.1$ \\
More developed regions & 1,014 & 7.5 & $7.3-7.8$ \\
Less developed regions & 7,685 & 8.8 & $8.1-9.4$ \\
Least developed regions & 4,171 & 12.5 & $11.7-13.3$ \\
& & & \\
Africa & 4,047 & 11.9 & $11.1-12.6$ \\
Asia & 6,907 & 9.1 & $8.3-9.8$ \\
$\quad$ Europe & 466 & 6.2 & $5.8-6.7$ \\
Latin America \& the Caribbean & 933 & 8.1 & $7.5-8.8$ \\
North America & 480 & 10.6 & $10.5-10.6$ \\
$\quad$ Oceania (Australia/New Zealand) & 20 & 6.4 & $6.3-6.6$ \\
\hline
\end{tabular}

Source: Beck S. et al. [21]

United States, great disparities exist between racial and ethnic groups-in both preterm birth rates and outcomes. The most striking differences are between African American women and non-Hispanic white, Asian and Pacific Islander women. In 2005, the preterm birth rates among these groups varied from $18.4 \%$ among African American to $11.7 \%$ among non-Hispanic white women and $10.8 \%$ among Asian and Pacific Islander women [26]. The overall preterm birth rate has increased since 1990, due primarily to a $38 \%$ increase in non-Hispanic white preterm births and a $10 \%$ increase in Hispanic preterm births [26].

American Indians and Alaska Natives also have high preterm birth rates, reported to be $13.5 \%$ in 2005 [27]. Among US Indigenous populations, Native Hawaiians experience the highest infant and neonatal mortality rates [27, 28]. The Pregnancy Risk Assessment Monitoring System (PRAMS) conducted by the US CDC estimates that one-half of infant deaths among Indigenous populations in the United States are attributable to low birth weight or preterm birth.

The recording of births and deaths, as well as the likelihood of medical intervention have been shown to be affected by medical caregivers' perceptions of viability of the baby. Babies that are very preterm may be less likely to be recorded or even to receive care despite reasonable chances of survival $[29,30]$. In countries without neonatal intensive care, few babies below the gestational age of 32 weeks survive and even at 30 weeks may be called "abortions" and not recorded [31]. This is very different than countries with intensive care, where although few babies born alive at 22 weeks may survive intact, by 25 weeks the majority survive [32, 33]. Hence even extremely preterm babies may be aggressively resuscitated 
Table 3. Trends in preterm births for selected countries

\begin{tabular}{|c|c|c|c|}
\hline \multirow[b]{2}{*}{ Country } & \multicolumn{2}{|c|}{ Preterm Births (Percent) } & \multirow{2}{*}{$\begin{array}{l}\text { Proportionate Change } \\
\text { from Previous Rate }\end{array}$} \\
\hline & Previously Reported Rates & Recently Reported Rates & \\
\hline \multicolumn{4}{|l|}{ High-Income Countries } \\
\hline Australia [79] & 5.9 (1994) & $6.6(2003)$ & $11.8 \%$ \\
\hline Canada [19] & $6.3(1982-1983)$ & $6.8(1992-1994)$ & $7.9 \%$ \\
\hline Finland [80] & $9.1(1966)$ & $5.2(2001-2005)$ & $-42.8 \%$ \\
\hline France [81] & $7.9(1972)$ & $4.0(1988-1989)$ & $-49.4 \%$ \\
\hline Israel [82] & $11.5(1986-1987)$ & $9.4(2003-2004)$ & $-18.3 \%$ \\
\hline Japan [83] & $4.1(1980)$ & $5.4(2000)$ & $24.4 \%$ \\
\hline New Zealand [84] & $4.3(1980)$ & 5.9 (1994) & $37.2 \%$ \\
\hline Scotland [85] & $4.9(1980-1984)$ & $5.6(2000-2003)$ & $14.3 \%$ \\
\hline United Kingdom & 4.6 (1971-1976)[35] & 6.0 (2002) [86] & $30.4 \%$ \\
\hline $\begin{array}{l}\text { United States [87] } \\
\text { Non-Hispanic white } \\
\text { Non-Hispanic black (African American) } \\
\text { Hispanic } \\
\text { All races }\end{array}$ & $\begin{array}{c}(1990) \\
8.5 \\
18.9 \\
11.0 \\
10.6\end{array}$ & $\begin{array}{l}(2005) \\
11.7 \\
18.4 \\
12.1 \\
12.7\end{array}$ & $\begin{array}{c}37.6 \% \\
2.6 \% \\
10.0 \% \\
19.8 \%\end{array}$ \\
\hline Sweden [88] & $6.3(1984)$ & $5.6(2001)$ & $-11.1 \%$ \\
\hline \multicolumn{4}{|l|}{ Middle-Income Countries } \\
\hline Brazil, Pelotas [89] & $11.4(1993)$ & $14.7(2004)$ & $26.9 \%$ \\
\hline Brazil, Ribeirão Preto [90] & $8.0(1978)$ & $14.8(1994)$ & $85.0 \%$ \\
\hline Brazil, regression based on all studies [38] & 4.0 (1980s) & 12.0 (2000s) & $200.0 \%$ \\
\hline Chile [91] & $5.6(1990)$ & $6.0(2000)$ & $7.1 \%$ \\
\hline China & $7.5(1981-1982)[35]$ & 3.5 (1998) [92] & $-53.3 \%$ \\
\hline Indonesia & $18.5(1983)[35]$ & $14.2(1995)[93]$ & $-23.2 \%$ \\
\hline Uruguay (unpublished data) & $10.1(1986-93)$ & $10.3(2000-2003)$ & $2.0 \%$ \\
\hline Latin America database [39] & $9.4(1985-1990)$ & $9.5(1996-2003)$ & $1.1 \%$ \\
\hline \multicolumn{4}{|l|}{ Low-Income Countries } \\
\hline Bangladesh & $22.0(1994-1997[94]$ & $16.5(2000)[95]$ & $-33.3 \%$ \\
\hline Gambia & $13.5(1976-1984)[35]$ & $12.3(1976-2003)[96]$ & $0.91 \%$ \\
\hline Nepal (rural) & $\begin{array}{c}\text { 15.8 (1990)-rural } \\
21.8 \text { (1990)-urban [35] }\end{array}$ & $23.1(1998-2001)[95,97]$ & $-8.9 \%$ \\
\hline Pakistan & $10.2([98] 1992-94)$ & $15.7(2001-02)[99]$ & $53.9 \%$ \\
\hline
\end{tabular}

and data fully recorded, although practices still vary between countries. The Nuffield Council on Bioethics recommends that below 22 weeks of gestation resuscitation should not be attempted, even if a baby is born with signs of life [34].

\section{Preterm birth prevalence trends}

Table 3 provides trends in preterm birth for a number of selected HICs and LMICs, including preterm prevalence in non-representative populations published by WHO in 1995 [35]. Reported preterm birth rates among European and other HICs range from $5 \%$ to $9 \%$, and similar to the United States, have been on the rise over the past three decades [36]. A significant contribution to the rise in preterm birth rates reflects an increase in preterm delivery due to medical indication of either the mother or the fetus. In absolute terms, however, medically-indicated preterm births made up less than half of all preterm births in the year 2000 in the United States [36, 37].

In LMICs, data on trends in preterm birth are very limited and results are mixed. In general, LMIC rates tend to be higher than in HICs. In Latin America, rates are increasing in Brazil, possibly related to elective cesarean sections and labor inductions [38]. In an analysis of more than 1.7 million births that took place in 51 maternity hospitals in Latin America, for which Uruguay and Argentina contributed half the births, the rates of preterm birth were essentially the same between 1985 


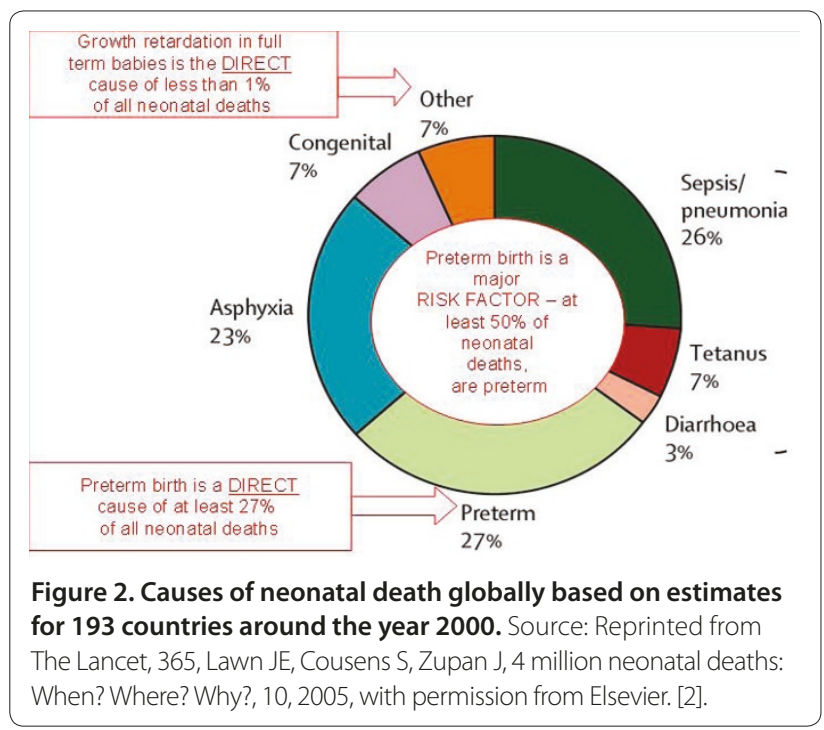

and 2003 (around 9\%). However, there was a marked increase in the proportion of preterm births associated with induction/elective caesarean sections during this period [39]. For countries outside of Latin America, such as China, Indonesia, and Bangladesh, the available studies use sub-national samples and should be interpreted with care.

\section{Preterm birth as a cause-of-death, acute morbidity, and disability}

Systematic estimates for the causes of neonatal deaths in 192 countries were undertaken by the CHERG based on vital registration data for 45 countries ( $\mathrm{N}=96,797$ deaths) and modelled estimates for 146 countries (input database of $\mathrm{N}=13,685$ deaths). These were published in The Lancet Neonatal Survival Series [2], incorporated in the World Health Report 2005 [40], and in Disease Control Priorities in Developing Countries [8, 41] (Figure 2). The methods are described in detail elsewhere and also summarized in Table 1. At the global level, these estimates place preterm birth as the single largest direct cause of the world's four million neonatal deaths [2].

In addition to being the leading direct cause of neonatal deaths (Figure 2), preterm birth also increases the risk of dying due to other causes, especially from neonatal infections [2]. An example is a moderately preterm baby who dies of infection after a few days of life. Hence, as well as being the leading direct cause of neonatal deaths, preterm birth is a crucial risk factor for neonatal deaths due to infection. A systematic risk factor analysis is planned (Table 1).

As shown in Figure 3, the proportion of neonatal deaths attributed to preterm births is inversely related to the rates of neonatal mortality, because in countries with very high neonatal mortality, more deaths occur due to

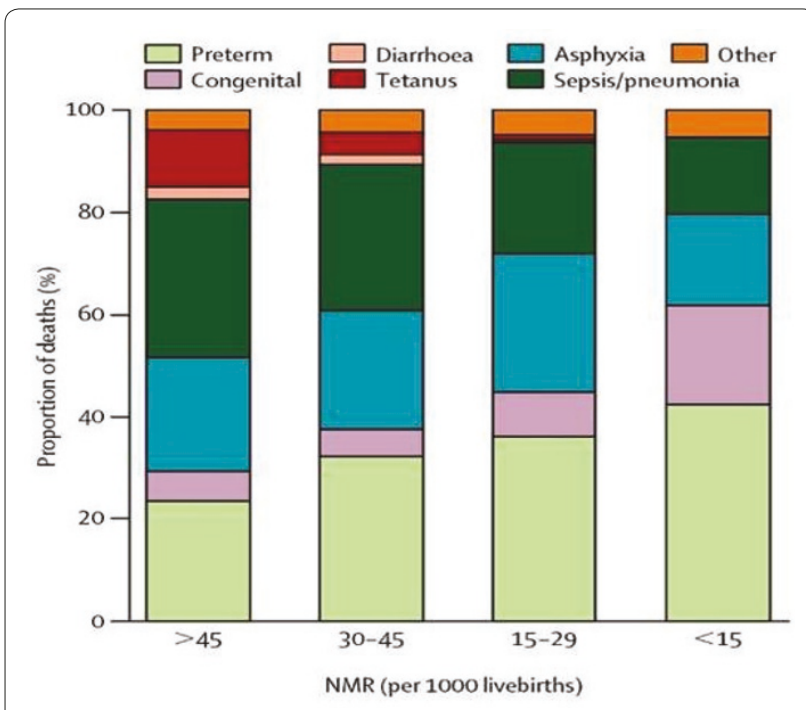

Figure 3. Percent distribution of neonatal causes of death by level of neonatal mortality showing the increasing proportion of neonatal deaths attributed to preterm birth with lower neonatal mortality rate. Source: Reprinted from The Lancet, 365, Lawn JE, Cousens S, Zupan J, 4 million neonatal deaths: When? Where? Why?, 10, 2005, with permission from Elsevier [2].

infections such as syphilis or tetanus, as well as to intrapartum-related "birth asphyxia" [2]. However, although the proportion of deaths due to preterm birth is lower in LMICs than in HICs, the cause-specific rates are much higher in LMICs than in HICs. For example, in Nigeria the estimated cause-specific rate for neonatal deaths directly due to preterm birth is 13.5 per 1000 compared to the UK where it is under 2 per 1000 . This is due to the lack of even simple care for preterm babies. Neonatal mortality rates are higher in LMICs than in HICs, partly because of poorer access to health services and quality of maternal and newborn interventions [5].

Mortality rates increase proportionally with decreasing gestational age (and hence decreasing birth weight). Mortality and morbidity are highest among infants born at less than 32 weeks gestation. Infants born from 32 to 36 weeks represent about $75 \%$ of all preterm births and the group of infants who make up the fastest-growing proportion of the preterm births in HICs, with a $25 \%$ increase during 1990-2005 [6]. While improvements in medical care have led to improved survival and longterm outcomes among moderately and extremely preterm babies in HICs, these babies still account for the majority of deaths, especially in LICs where even simple care is lacking.

In Southern Brazil, preterm babies experience high mortality rates due to respiratory infections, diarrhea, and other infections that were eight, five, and six times higher, respectively, than rates of term babies [42]. In the United States during 1995-2002, the mortality rate for 
term newborns was 2.4-3.0 per 1,000 live births. Among babies who were born between 34 and 36 weeks gestation, the mortality rate was $7.9-9.5$ per 1,000 live births [43]. Few studies in the literature evaluate gestational age-specific neonatal mortality rates. The comparison of three such studies in Table 4 illustrates the differences in survival among low-, middle-, and highincome countries.

The major focus in HICs is now on the extremes of gestational age and survival. In a comparative analysis of data from France and England in 1997, 19\% and 27\% of babies born at less than 26 weeks survived to discharge; $57 \%$ and $68 \%$ of those born at $26-28$ weeks gestation survived to discharge; and $86 \%$ and $92 \%$ of those born at 28-32 weeks survived to discharge, respectively [44]. In a cohort of extremely preterm infants from the United Kingdom from 1995, 26\% of babies born at 24 weeks survived to discharge, and among those born at 25 weeks, $44 \%$ survived to discharge [45]. Similarly, in a Canadian cohort of babies born between 1996 and 1997, 57\% of babies born at 24 weeks and $76 \%$ of babies born at 25 weeks survived to discharge [46].

\section{Preterm morbidity and long-term sequelae}

The complications of preterm birth arise from immature organ systems that are not yet prepared to support life in the extrauterine environment. The response of the infant's organ systems to the demands of the extrauterine environment and the life support provided have an important impact on the infant's short- and long-term health and neurodevelopmental outcomes. These outcomes are also influenced by the etiology of the preterm birth; maternal and family risk factors; and the extrauterine environment, including the neonatal intensive care unit; and the home and community.

Babies born preterm have an increased risk of morbidity due to different mechanisms. Some are directly related to their immaturity, as with hyaline membrane disease due to the lack of pulmonary surfactant, and retinopathy of prematurity due to the excessive use of oxygen to treat hyaline membrane disease. Preterm birth may also be a marker for other problems that produce disease, such as fetal infection and systemic inflammation, which are themselves associated with intracranial haemorrhage, cerebral white matter damage, cerebral palsy, and chronic lung disease (bronchopulmonary dysplasia) [47].

\section{Stillbirth burden}

\section{Defining stillbirth}

The International Classification of Diseases, $10^{\text {th }}$ revision (ICD-10) [48] defines a fetal death as "death prior to the complete expulsion or extraction from its mother of a product of conception, irrespective of the duration of
Table 4. Gestational age-specific neonatal mortality rates by 1,000 live births for preterm babies

\begin{tabular}{lccc}
\hline $\begin{array}{l}\text { Gestational Age } \\
\text { (weeks) }\end{array}$ & $\begin{array}{c}\text { Ilesa, Nigeria, } \\
\mathbf{1 9 9 6 - 2 0 0 0}\end{array}$ & $\begin{array}{c}\text { Pelotas, Brazil, } \\
\mathbf{2 0 0 4}\end{array}$ & $\begin{array}{c}\text { Scotland, } \\
\mathbf{1 9 8 5 - 1 9 9 4}\end{array}$ \\
\hline $34-36$ & 48 & 15 & 11 \\
$32-33$ & 156 & 61 & 33 \\
$<32$ & 587 & 370 & 194 \\
All preterm (<37) & 179 & 66 & 41 \\
\hline
\end{tabular}

Source: Ilesa, Nigeria (1996-2000) [100], Pelotas, Brazil (2004) (Barros, personal communication 2009), and Scotland (1985-1994) [101]

pregnancy; the death is indicated by the fact that after such separation the fetus does not breathe or show any other evidence of life, such as beating of the heart, pulsation of the umbilical cord, or definite movement of voluntary muscles" without specification of the duration of pregnancy. Although birth weight has been the preferred criterion in the ICD to identify a late fetal death, gestational age is an additional requirement for reporting for international comparative purposes. ICD classifies late fetal deaths (greater than 1000 gms or after 28 weeks) and early fetal deaths (500 to 1000 gms or 22-28 weeks) (Table 5).

It should be noted that "stillbirth" is not a technical term. In this article "stillbirth" refers to late fetal deaths to conform to the WHO recommendation that late fetal deaths be reported for purposes of international comparison. The rationale for restricting international reporting to stillbirths of greater than 1000 gms or after 28 weeks is to assure comparability, as the countries where most stillbirths occur mostly still do not capture even these larger more mature deaths reliably and data remain uncertain [49]. In countries lacking neonatal intensive care, few babies below the gestational age of 30 weeks survive [31]. However, in many countries where neonatal intensive care units are available, the gestational age for viability has decreased, and the gestational age criterion to define stillbirth has been adapted accordingly. Current gestational age thresholds for stillbirth vary from 16 to 28 weeks of gestation across countries.

\section{Stillbirth rates estimates}

Prior to 2006, no organization had published global, regional or country-specific stillbirth rates. Two global series of stillbirth estimates for the year 2000 were published in 2006 (hereafter referred to as the SNL/immpact and WHO estimates) $[7,50]$, with both exercises generating estimates of just over three million stillbirths (3.2 million, with wide uncertainty: 2.5-4.1 million; and 3.3 million, respectively). SNL/immpact represents a collaboration between Saving Newborn Lives/Save the Children USA and the Initiative for Maternal Mortality Programme Assessment, at the University of Aberdeen, Scotland. 

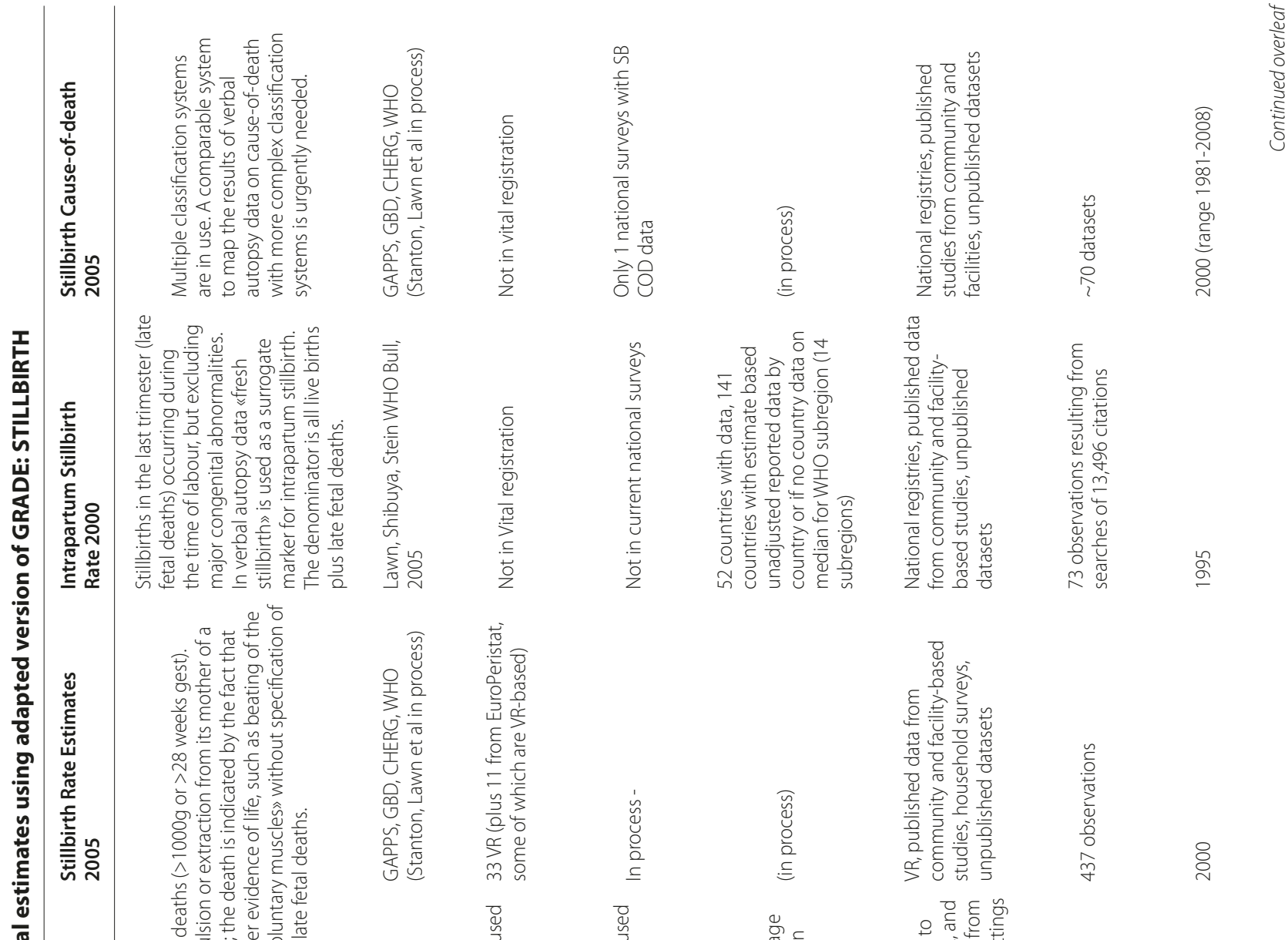

훌

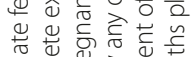

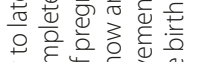

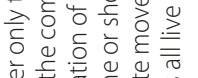

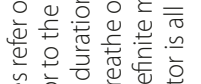

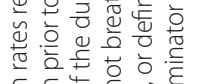

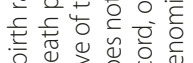
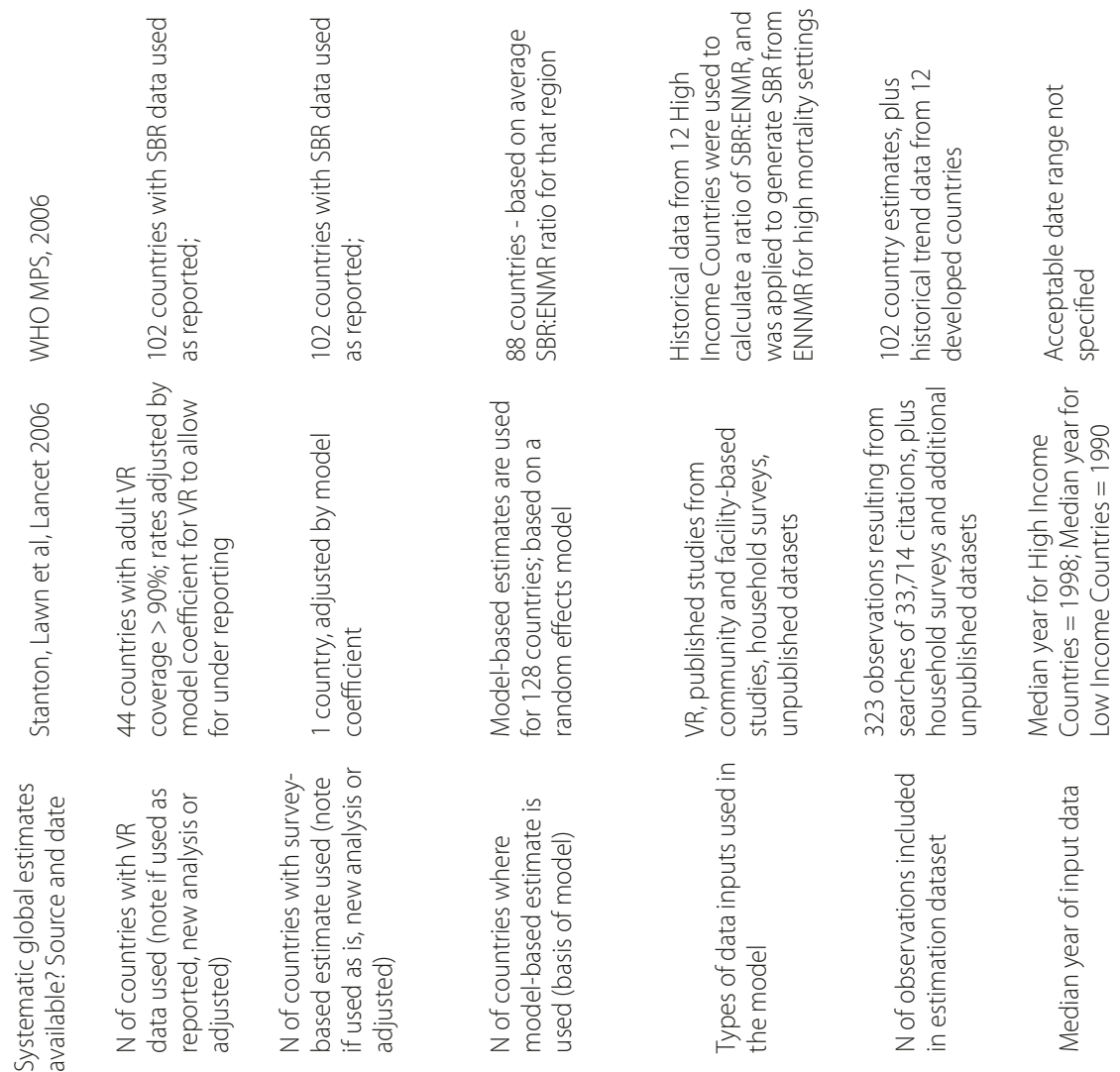


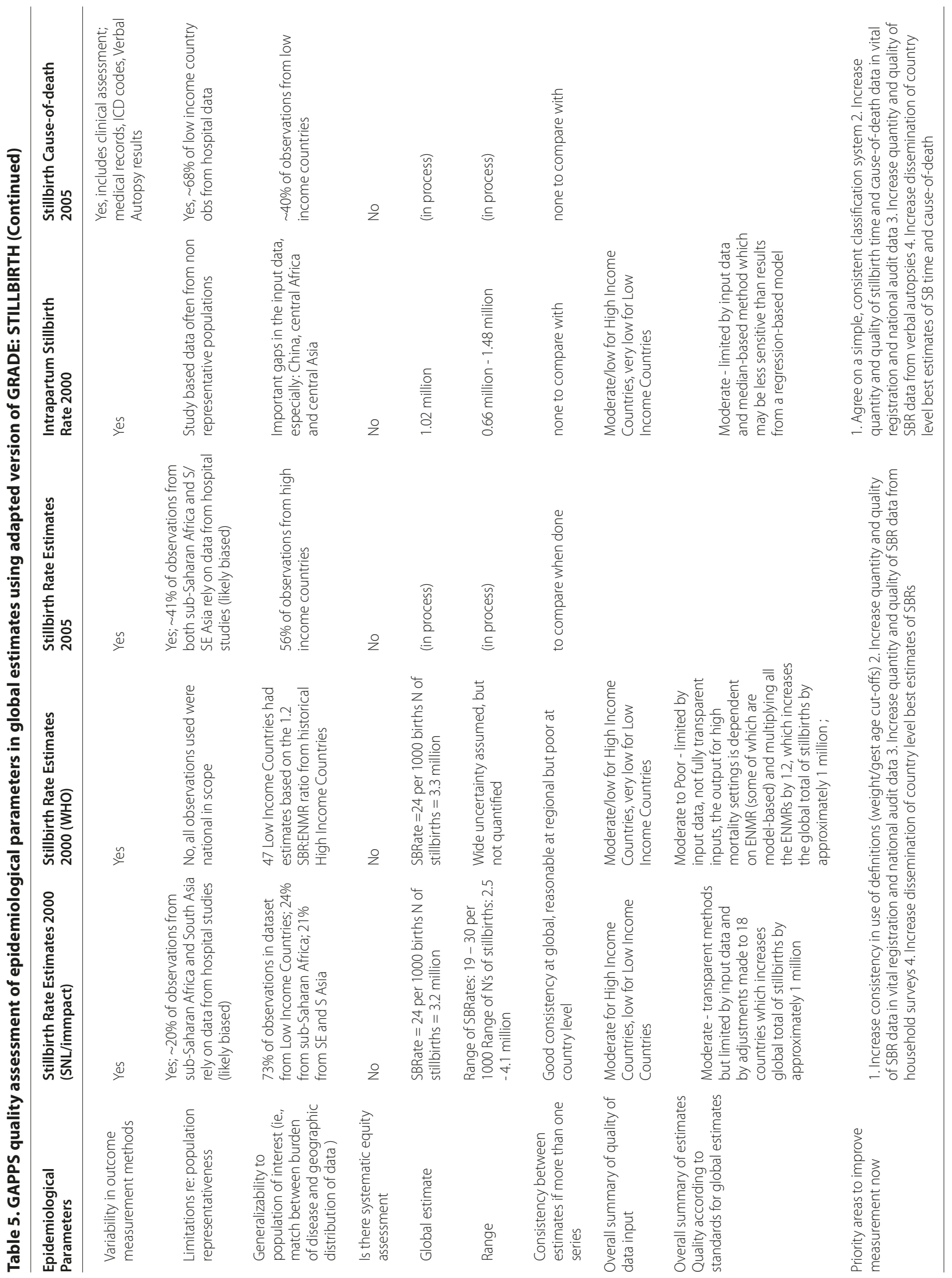




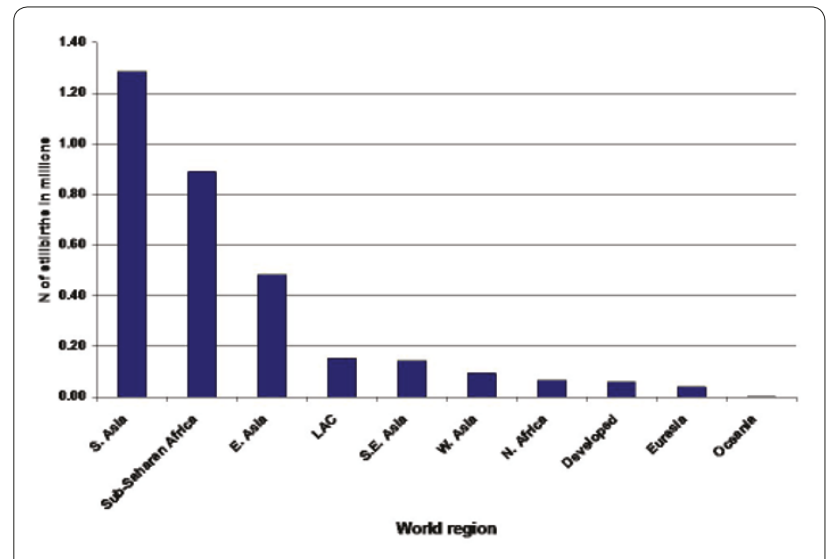

Figure 4. Estimated global number of stillbirths by world region, 2000. Source: Reprinted from The Lancet, 367, Stanton C, Lawn JE, Rahman H, Wilczynska-Ketende, K, Hill K, Stillbirth rates: delivering estimates in 190 countries, 8, 2006, with permission from Elsevier [7].

Figure 4 presents the SNL/immpact numbers of stillbirth by region.

Given the very different methods used in these two estimation exercises and the dearth of stillbirth data available from developing countries, the results are remarkably similar. Table 6 summarizes regional stillbirth rates from the two series of estimates. Stillbirth rates are very similar for sub-Saharan Africa and South Asia (32 per 1000 births). However, there is little agreement between the remaining regional estimates and even less agreement at the country level, where the data are most needed for planning purposes; for example, two- to three-fold differences in both directions exist between the two series of estimates for some countries (data not shown). Figure 4 presents the estimated number of stillbirths by world region.

The methods for both series of stillbirth estimates have been summarized in Table 5. Any global estimation exercise is by definition an attempt to make the best of sub-optimal data. Both series of estimates suffer from a lack of quantity and of quality input data. This leads to decisions in the modelling process that are easy targets for criticism. Our summary assessment of these two exercises is "moderate" at best when judged according to the criteria outlined in Table 5. An updated series of stillbirth rates and numbers for 2005 will be undertaken jointly by WHO and CHERG with GAPPS and undergo external review prior to the next global burden of disease exercise.

\section{Availability of stillbirth rate data}

In HICs, national vital registration systems usually have high coverage and reasonably reliable cause-of-death data for live births, but the stillbirth data are often more questionable [7]. Globally, only about $2 \%$ of late stillbirths
Table 6. Comparison of stillbirth rate estimates at regional levels

\begin{tabular}{|c|c|c|}
\hline \multirow[b]{2}{*}{$\begin{array}{l}\text { World Region } \\
\text { (WHO regions) }\end{array}$} & \multicolumn{2}{|c|}{ Stillbirth Rate per 1,000 births } \\
\hline & $\begin{array}{l}\text { WHO } \\
\text { estimate }\end{array}$ & $\begin{array}{c}\text { SNL/immpact estimate } \\
(95 \% \mathrm{Cl})\end{array}$ \\
\hline World & 24 & $23.9(18.8-30.5)$ \\
\hline HICs & 4 & $5.3(4.2-6.8)$ \\
\hline LMICs & 26 & $25.5(20.0-32.5)$ \\
\hline North Africa & 16 & $18.6(14.1-24.7)$ \\
\hline Sub-Saharan Africa & 34 & $32.2(25.4-40.9)$ \\
\hline Latin America/Caribbean & 10 & $13.2(10.4-16.7)$ \\
\hline East Asia & 19 & $23.2(18.3-29.5)$ \\
\hline South Asia & 34 & $31.9(25.0-40.7)$ \\
\hline Southeast Asia & 18 & $12.7(10.0-16.0)$ \\
\hline West Asia & 16 & $18.9(14.3-24.9)$ \\
\hline Eurasia & 23 & $12.2(9.5-15.5)$ \\
\hline Oceania & 17 & $15.8(12.4-20.1)$ \\
\hline
\end{tabular}

Sources: $[7,50]$

are accounted for via vital registration. In countries lacking complete vital registration on stillbirths, but with high institutional birth rates, health facility-based data are also an important source of representative data on pregnancy outcomes. In LMICs, by far the largest source of data on stillbirths comes from population-based household surveys. Other sources include demographic surveillance sites, or special studies. In LMICs lacking high institutional birth rates, health facility data can still be a valuable resource if compiled regionally or nationally, especially if selection bias is taken into account. Notable examples are the Latin American Center for Perinatology (CLAP) database [51] and the South African Perinatal Identification Programme [52, 53].

\section{Stillbirth causes of death}

Currently there are no global, systematic estimates for stillbirth causes of death. Where data do exist, the lack of comparability across studies greatly inhibits interpretation. More than 30 different stillbirth classification systems have been identified in the literature [54], with some encompassing up to 37 causes [55]. Most focus on stillbirths in HICs where determination of the most prevalent causes requires fetal surveillance and sophisticated diagnostics [49]. Later in the article, options for improving stillbirth cause-of-death comparability will be discussed.

Comparable data regarding the timing of stillbirths relative to delivery are more widely available. Intrapartum stillbirths are generally defined as stillbirths occurring after the onset of labour, or as "fresh stillbirths" (with skin still intact, implying death occurred less than 


\section{Intrapartum stillbirths estimation process}

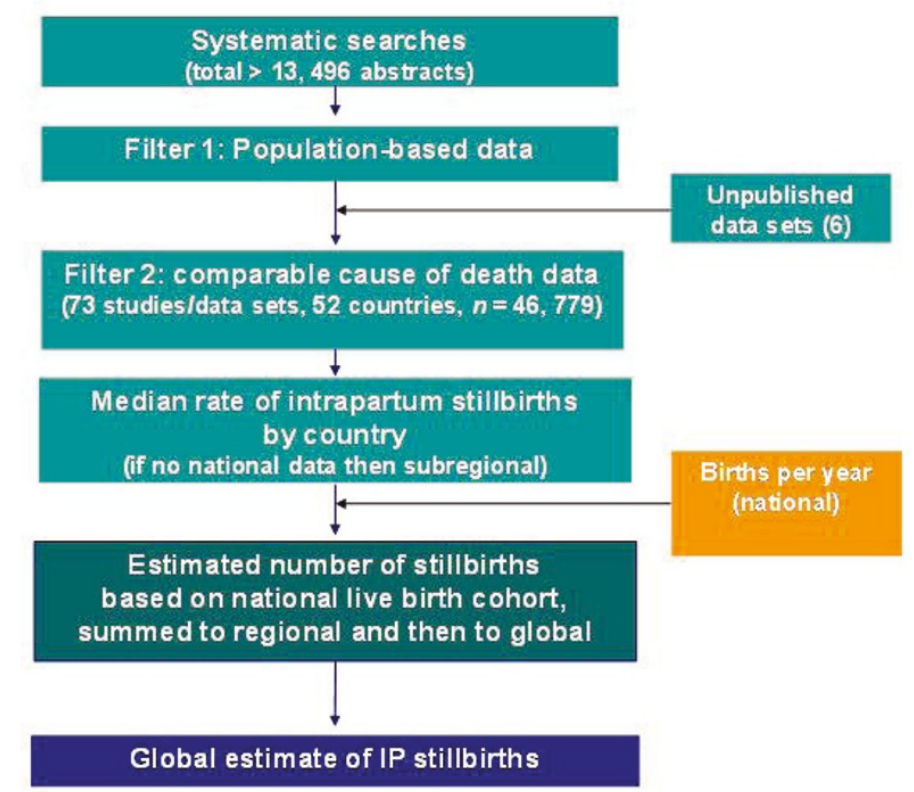

Figure 5. Data sources and methods for estimates of intrapartum stillbirth rates for 192 countries. Source: Reprinted from Bulleting of the World Health Organization, Lawn JE, Shibuya K, Stein C, No cry at birth: global estimates of intrapartum stillbirths and intrapartum-related neonatal deaths, 2005, with permission from WHO Press [56].

12 hours before delivery) weighing more than 1,000 grams and more than 28 weeks of gestation, but exclude severe lethal congenital abnormalities [56]. This increased availability of data permitted publication in 2005 of intrapartum stillbirth rates for 192 countries. Details regarding the input data for this series of estimates are included in Figure 5 and methods are summarized in Table 5.

Based on these estimates, one million intrapartum stillbirths occur annually (uncertainty bounds: 0.66-1.48), representing one-third of stillbirths globally [56]. Despite the caveats inherent in the interpretation of the intrapartum stillbirth estimates, these estimates clearly highlight the magnitude of loss of life just minutes and hours prior to birth. Hospital-based studies suggest that from 25-62\% of intrapartum stillbirths are avoidable with improved obstetric care and more rapid responses to intrapartum complications, including reducing delays in seeking care from home [57-60].

At the time of writing of this supplement, a systematic review of the literature on stillbirth cause-of-death is underway. Data permitting, the distribution of causes of stillbirth will be estimated, using methods similar to those used to estimate neonatal cause-of-death [61]. Approximately 65 studies from 36 countries have been identified that provide at least minimal stillbirth causeof-death data. Data have been extracted into the following categories: congenital abnormality (physically visible); maternal conditions (including pregnancyinduced hypertension, eclampsia/preeclampsia, diabetes, other antenatal); antepartum hemorrhage (abruption); infections (including syphilis, other maternal and other fetal infection); intrapartum stillbirth (including obstruction, and breech); preterm labor of undetermined cause; other and unclassifiable.

\section{Opportunities to improve data on preterm births and stillbirths}

Preterm birth data improvement

Improving measurement of preterm birth prevalence

There are many opportunities to improve data now in both low- and high-income countries (Table 7). The definition for preterm birth (less than 37 weeks of completed gestation) is well-known. The challenge is the current low priority given to collecting gestational age data, and the complexity of measurement (apart from the use of last menstrual period). Further effort is needed to influence the content of midwifery and medical pre- and in-service education and to establish gestational age assessment as an integral component of routine care.

In HICs, gestational age assessment has surpassed birth weight as the measurement of choice, with a much closer correlation to short- and long-term outcomes. A number of methods exist for the assessment of gestational age. In 
Table 7. Improving country level data for preterm birth - what can be done now and what are the research priorities?

\begin{tabular}{|c|c|c|c|}
\hline \multirow[b]{2}{*}{ Opportunities } & \multicolumn{2}{|c|}{ Opportunities Immediately Available } & \multirow{2}{*}{$\begin{array}{l}\text { Research Priorities (Focus on high } \\
\text { mortality, low quality data settings) }\end{array}$} \\
\hline & High-Income Settings & Low-Income Settings & \\
\hline $\begin{array}{l}\text { Comparable case } \\
\text { definitions and better } \\
\text { definitions of } \\
\text { phenotypes }\end{array}$ & $\begin{array}{l}\text { Use } 37 \text { completed weeks of gestation } \\
\text { but also advance data for very preterm } \\
\text { (<34 weeks) and moderate (34-36.9) as } \\
\text { well as for spontaneous and medically } \\
\text { induced preterm birth }\end{array}$ & $\begin{array}{l}\text { Prioritize improved collection of } \\
\text { representative population-based data } \\
\text { preterm prevalence as a key starting } \\
\text { point }\end{array}$ & $\begin{array}{l}\text { Development of simple and feasible proxy } \\
\text { indicators for gestational age (e.g., weight) }\end{array}$ \\
\hline $\begin{array}{l}\text { Mechanisms for } \\
\text { data collection }\end{array}$ & $\begin{array}{l}\text { Include gestational age and birth } \\
\text { weight data on birth certificates and } \\
\text { perinatal death certificates. Cross-link } \\
\text { data from vital registration and health } \\
\text { facility surveillance. }\end{array}$ & $\begin{array}{l}\text { Improve vital registration systems. } \\
\text { Use specific death certificates for } \\
\text { stillbirths/neonatal deaths and include } \\
\text { gestational age and birth weight data } \\
\text { on birth certificates }\end{array}$ & $\begin{array}{l}\text { Validation of approaches to assess gestational } \\
\text { age through household survey data }\end{array}$ \\
\hline $\begin{array}{l}\text { Cause-of-death } \\
\text { attribution } \\
\text { mechanisms }\end{array}$ & $\begin{array}{l}\text { Use vital registration specific death } \\
\text { certificates for stillbirth and neonatal } \\
\text { deaths. } \\
\text { Revise current ICD codes for preterm } \\
\text { birth to reflect change in focus from } \\
\text { birth weight to gestational age }\end{array}$ & $\begin{array}{l}\text { In large-scale surveys, follow-up } \\
\text { interviews with a verbal autopsy for } \\
\text { recent stillbirth and neonatal deaths. } \\
\text { Use standardized verbal autopsy tool, } \\
\text { case definitions and hierarchical } \\
\text { attribution for cause-of-death. Provide } \\
\text { clear guidelines for when to attribute } \\
\text { death to preterm complications. }\end{array}$ & $\begin{array}{l}\text { Evaluation of the use and reliability of a } \\
\text { standardized verbal autopsy tool, case } \\
\text { definitions and hierarchy of causes of death. } \\
\text { Development of verbal autopsy classification } \\
\text { software which provides greater consistency } \\
\text { and costs less than expert assessment of } \\
\text { verbal autopsy data }\end{array}$ \\
\hline $\begin{array}{l}\text { Counting avoidable } \\
\text { factors, using data } \\
\text { in programmes }\end{array}$ & $\begin{array}{l}\text { Increase the number of national audit } \\
\text { systems } \\
\text { Consider confidential enquiry for } \\
\text { neonatal deaths and stillbirths, as well } \\
\text { as maternal deaths }\end{array}$ & $\begin{array}{l}\text { Develop or modify audit systems } \\
\text { linking maternal/fetal and neonatal } \\
\text { deaths. Compile national data and/or } \\
\text { promote sentinel sites in varying health } \\
\text { system contexts to ensure that the } \\
\text { information is useful for policy } \\
\text { prioritization, even if not representative } \\
\text { of the population. } \\
\text { Consider focusing on few indicators } \\
\text { initially (e.g. Intrapartum Case Fatality } \\
\text { Rate). } \\
\text { Use existing data (e.g., facility birth } \\
\text { registers) for local monitoring and } \\
\text { programmatic decision-making. }\end{array}$ & $\begin{array}{l}\text { Evaluation of simple audit tools and a } \\
\text { mechanism to maximize resultant change in } \\
\text { policy and programs. }\end{array}$ \\
\hline
\end{tabular}

middle-income countries, gestational age is increasingly available, even with ultrasound dating (the gold standard). In most countries, a very small proportion of births have reliable gestational age assessment. Even estimates of gestational age based on last menstrual period are often not recorded or known, particularly in African settings. In most survey-based data, women are asked to state their gestational age in completed months. This is the practice in the DHS contraceptive calendar, for example.

\section{Option 1: Birth weight as a surrogate measure}

In LMICs, low birth weight is often used as the criterion for identifying preterm births given the paucity and quality of self-reported data on gestational age. Reliance on LBW is problematic, however, as $58 \%$ of babies in LMICs are not weighed at birth (Table 8), and homebased births, those most likely to be of low birth weight, are not represented [23]. In middle-income countries, notably in Latin America, many countries have a record of birth weight for the majority of babies (83\%), but in South Asia and sub-Saharan Africa, where the majority of neonatal deaths occur, only a fourth to a third of babies
Table 8. Percent of live births that are not weighed by world region

\begin{tabular}{lc}
\hline World Region (UNICEF) & Percent of Births NOT Weighed at Birth \\
\hline South Asia & 74 \\
Sub-Saharan Africa & 65 \\
Middle East and North Africa & 60 \\
East Asia and Pacific & 30 \\
CEE/CIS & 21 \\
Latin America and Caribbean & 17
\end{tabular}

Source: Data from Blanc AK, Wardlaw T, 2005 [23]

have a record of birth weight. These figures parallel the coverage of skilled attendance at birth, though even with a facility-based birth by a skilled attendant, the birth weight may not be recorded due to a lack of scales, skilled staff, and standard protocols [13].

Table 9 shows the proportion of preterm babies in different birth weight groups. Only about half of the newborns at 2000-2499-grams were born preterm. These data suggest that using a cut-off of 2000 grams may be more appropriate than the traditional LBW definition in 
Table 9. Distribution of preterm births according to birthweight group.

\begin{tabular}{lcc}
\hline $\begin{array}{l}\text { Birth Weight } \\
\text { (Grams) }\end{array}$ & $\begin{array}{c}\text { Uruguay } \\
\mathbf{1 9 8 6 - 2 0 0 3} \\
(\mathbf{n}=\mathbf{4 7 6 , 5 7 1 )}\end{array}$ & $\begin{array}{c}\text { Pelotas } \\
\mathbf{1 9 8 2}, \mathbf{1 9 9 3}, \mathbf{2 0 0 4} \\
(\mathbf{n}=\mathbf{1 4 , 1 1 7})\end{array}$ \\
\hline $3,000+$ & $3.0 \%$ & $3.4 \%$ \\
$2,500-2,999$ & $14.6 \%$ & $13.4 \%$ \\
$2,000-2,499$ & $49.0 \%$ & $45.0 \%$ \\
$1,500-1,999$ & $84.8 \%$ & $88.7 \%$ \\
$<1,500$ & $93.4 \%$ & $97.5 \%$ \\
All & $10.7 \%$ & $11.0 \%$ \\
\hline
\end{tabular}

Source: PAHO/WHO Latin American Center for Perinatal Health (Barros, unpublished permission granted by author)

identifying preterm births. The two studies described in Table 9 are from Latin America, and these proportions may differ in other regions, such as South Asia where intrauterine growth restriction is highly prevalent. When data are available for birth weight and age-at-death of stillbirths and neonatal deaths, a simple cross tabulation of birth weight by age-at-death can be a useful guide for programmatic priority setting [62]. For example, full-size babies dying during birth have very different solutions to very small babies dying after birth.

\section{Option 2: Clinical assessment of gestational age}

Given the need for a paradigm shift to use gestational age instead of birth weight for the identification of preterm births, the possibility of simplified gestational age assessment by lower cadres of workers is of interest. A recent systematic review of methods for gestational age assessment identified 17 different methods using a combination of neurological and physical criteria or physical criteria alone [63]. Methods requiring complex technology or neurological assessment alone were excluded. Of these 17 methods, five were considered "complex," nine were "intermediate," and three were "simple," based on the number of characteristics examined.

As compared against varying standards (only some of which were ultrasound) all methods were accurate within plus or minus three weeks. The number of methods to choose from and the varying levels of complexity allow for recommendations to be made appropriate to two settings: tertiary care hospitals and district-level health facilities. Further uptake of these methods are needed by international and medical professional associations to influence the content of midwifery and medical pre- and in-service education as a means of establishing gestational age assessment as an integral component of routine care. Evaluation of use at large-scale settings and data validity could further refine recommendations by setting. However, none of the methods which were compared against an acceptable standard were applied by community health workers. Hence, further research is required to identify the most feasible and acceptably accurate methods for community-based gestational age assessment.

\section{Improving measurement of other parameters related to the burden of preterm birth}

A new analysis would be required to better delineate the effect of preterm compared to term gestational age, to define the risk of varying gestational ages for death, and to separate direct from indirect risks. Individual-level data on birth weight, gestational age, mortality outcome and ideally comparable cause-specific mortality would be required for such an analysis (Table 1 ).

To improve the assessment of long-term outcomes of preterm birth, particularly impairment outcomes, an international consensus group is required to agree to standard definitions for these parameters. Protocols and tools are required to ensure standard measurement, especially for disability and cognitive function at various ages.

\section{Stillbirth data improvement}

\section{Improving the data on stillbirth rates and numbers}

Table 10 summarizes a number of opportunities that are immediately available to improve stillbirth data through existing data collection mechanisms.

Option 1 - Vital registration

Improved measurement of stillbirths in HICs requires a focus on highly standardized reporting of stillbirths via vital registration or other comprehensive national registries. The most important data intervention is the establishment of a stillbirth death certificate. Given the plethora of data available from HIC health facilities, standardized reporting is entirely feasible. At issue is the political will to demand such an intervention. Establishment of a stillbirth death certificate could address both improved counting of events, as well as improved standardization of the causes of stillbirth.

In LMICs, one should capitalize on the current increased interest in improving vital registration by also introducing a standard perinatal death certificate. Complete registration may be a distant goal, but as the foundation for improved data is being established, stillbirths should be included or countries will miss the opportunity to show mortality change concurrent with the implementation of maternal and neonatal programs.

At the international level, seizing the opportunity of the upcoming revision of ICD codes to reflect recent advances in diagnosing stillbirth cause-of-death is essential to future data improvement. Regarding the identification of avoidable factors for the prevention of stillbirth, expanding the use of national audits or other forms of confidential inquiry is recommended. In addition to 
Table 10. Improving country level data for stillbirths - what can be done now and what are the research priorities?

\begin{tabular}{|c|c|c|c|}
\hline \multirow[b]{2}{*}{ Opportunities } & \multicolumn{2}{|c|}{ Opportunities Immediately Available } & \multirow{2}{*}{$\begin{array}{l}\text { Research Priorities (Focus on high } \\
\text { mortality, low quality data settings) }\end{array}$} \\
\hline & High-Income Settings & Low-Income Settings & \\
\hline $\begin{array}{l}\text { Comparable case } \\
\text { definitions for stillbirth }\end{array}$ & $\begin{array}{l}\text { Use } 28 \text { week cut-off for international } \\
\text { comparisons and } 22 \text { week cut-off for } \\
\text { High-Income Country comparisons. } \\
\text { Local definitions can be used for } \\
\text { local purposes. }\end{array}$ & $\begin{array}{l}\text { Prioritize improved collection of } \\
\text { representative population-based data } \\
\text { for last trimester and intrapartum } \\
\text { stillbirths. }\end{array}$ & $\begin{array}{l}\text { Development of simple and feasible proxy } \\
\text { indicators for gestational age (e.g., weight) }\end{array}$ \\
\hline $\begin{array}{l}\text { Mechanisms for } \\
\text { counting all births, } \\
\text { (including stillbirths) }\end{array}$ & $\begin{array}{l}\text { Improve vital registration data by } \\
\text { establishing specific death certificates } \\
\text { for stillbirth and neonatal deaths. } \\
\text { Cross-link data from vital registration } \\
\text { and health facility surveillance. }\end{array}$ & $\begin{array}{l}\text { Increase attention to training and field } \\
\text { supervision for DHS-type household } \\
\text { surveys which rely on retrospective } \\
\text { reporting of all births. Consider adding } \\
\text { stillbirth data collection to MICS surveys. } \\
\text { Analyze existing pregnancy loss data } \\
\text { from sentinel surveillance sites and } \\
\text { increase the number of sentinel } \\
\text { surveillance sites which prospectively } \\
\text { collect stillbirth data. } \\
\text { Improve vital registration systems and } \\
\text { register stillbirths. Use specific death } \\
\text { certificates for stillbirths/neonatal deaths. }\end{array}$ & $\begin{array}{l}\text { Validation of existing approaches for } \\
\text { pregnancy loss data collection compared to } \\
\text { pregnancy loss data from sentinel surveillance } \\
\text { sites }\end{array}$ \\
\hline
\end{tabular}

Classification for stillbirth cause-of-death

Cause-of-death attribution mechanisms

Counting avoidable factors, using data in programmes

Obtain consensus on a single classification system with a limited number of programmatically relevant, comparable categories, that can be distinguished in low income settings through verbal autopsy, but can also be directly incorporated into more detailed sub groups necessary in high income settings

Use vital registration specific death certificates for stillbirth and neonatal deaths.

Revise current ICD codes for stillbirths to reflect changes in attribution of cause-of-death since the 1980s.

Increase the number of national audit systems.Consider confidential enquiry.

\begin{abstract}
In large-scale surveys, follow-up interviews with a verbal autopsy for recent stillbirth and neonatal deaths. Use standardized verbal autopsy tool, case definitions and hierarchical attribution for cause-of-death.
\end{abstract}

Develop or modify audit systems linking maternal/fetal and neonatal deaths. Compile national data and/or promote sentinel sites in varying health system contexts to ensure that the information is useful for policy prioritization, even if not representative of the population. Consider focusing on few indicators initially (e.g. Intrapartum Case Fatality Rate).

Use existing data (e.g., facility birth registers) for local monitoring and programmatic decision-making.
Evaluation of validity and feasibility of a simple standard classification system for stillbirth cause-of-death

Evaluation of the use and reliability of a standardized verbal autopsy tool, case definitions and hierarchy of causes of death. Development of verbal autopsy classification software which provides greater consistency and costs less than expert assessment of verbal autopsy data

Evaluation of simple audit tools and a mechanism to maximize resultant change in policy and programs.

Abbreviations: Demographic Health Surveys (DHS), Multiple Indicator Cluster Surveys (MICS)

investigating traditional deficiencies in quality of care, these audits can be adapted to specific contexts to also examine socioeconomic disparities and demographic or behavioral characteristics of the population of interest.

Option 2 - Population-based surveys

The Demographic and Health Survey (DHS) website has posted national data on stillbirth rates for 49 surveys from 38 countries [64]. These surveys are by far the largest source of national data from LMICs. Given the lack of vital registration data on stillbirths in LMICs, reliance on survey-based estimates is inevitable for the near future, and given that $98 \%$ of stillbirths occur in LMICs - this data source cannot be ignored. The majority of DHSs consist of a complete live birth history for each woman of reproductive age in the sample. Many also include a contraceptive calendar in which monthly data on each respondent's contraceptive use, pregnancy status, and pregnancy outcomes are collected for the 60-month period prior to interview. These data permit calculation of stillbirth rates.

DHS stillbirth rates range from 3.4 per 1000 (in Ukraine) to 37.0 per 1,000 (in Bangladesh). Excluding the surveys in Bangladesh and Nepal, DHS stillbirth rates do not surpass 20 per 1,000. However, the Bangladesh DHS estimate is similar to the high-quality estimate from demographic surveillance data in Matlab, Bangladesh [65]. 
Evidence from countries with adequate historical data suggest that an SBR:ENMR ratio of approximately 1.2 can be expected in high mortality countries [50]. Only 5 of the 49 DHS surveys show ratios greater than one. For sub-Saharan African countries, the regional (populationbased) ratio is only 0.55 , and ranges from $0.61-0.64$ for the remaining regions, suggesting extreme under-reporting in the large majority of these countries. Moldova stands out as an extreme outlier with a ratio of 3.2, suggesting likely misclassification between stillbirths and early neonatal deaths. In a separate analysis of stillbirth rates from multiple data sources, DHS calendar-based stillbirth estimates were found to be approximately $30 \%$ lower than other population-based studies, after controlling for other study and population characteristics [7]. As currently implemented, the contraceptive calendar is not a reliable source of stillbirth data.

Over the past 20 years limited research attention has been applied as to how best to collect population-based pregnancy loss data. In 1989, Casterline analyzed the pregnancy loss data in 41 World Fertility Surveys and concluded that these pregnancy histories in their various formats detected from $50-85 \%$ of recognizable pregnancy losses, as compared to results from prospective, clinical studies in Western countries [66]. As expected, late fetal losses tended to be better reported than earlier miscarriages. Garenne noted the highly reliable reporting on perinatal mortality in Niakhar, Senegal, when comparing pregnancy history data to DSS data [67]. Goldman et al. [68], Westoff et al. [69], and Becker and Sosa [70] studied the effects of using a truncated pregnancy history in Peru, the Dominican Republic, and Costa Rica, with varying results depending on the outcome studied. Stanton found the reliability of reporting stillbirths in two national DHS-type surveys using pregnancy histories from the Philippines to be lower than for early neonatal or infant deaths [71].

To date the most rigorous examination of the validity of self-reported pregnancy outcome data was undertaken by Espeut in Bangladesh: comparing DSS data from Matlab, Bangladesh, matched to respondents in a DHS survey in which respondents were randomly assigned a questionnaire with a live birth or pregnancy history. In summary, a $91 \%$ sensitivity rate was found for reporting in the survey on stillbirths. In contrast, the sensitivity rate for early neonatal deaths varied from $79-81 \%$ in live birth and pregnancy histories; among stillbirths in the DSS, 3\% were misclassified as live births, and 9\% were misclassified as abortions (suggesting difficulty in recalling gestational age) compared to self-report in the surveys [72]. The goal of future validation efforts should not be restricted to identification of the highest quality approaches but should quantify the loss of data quality in choosing, for example, a truncated vs. complete live birth or pregnancy history, or a survey covering wide-ranging issues vs. a highly focused questionnaire. Immediate progress can be made by carefully reviewing the wide variation in current data collection processes-including the formulation of questions that would elicit reporting on pregnancy losses. Likewise, assuring increased attention to the definition of stillbirth during interviewer training and improving supervision in the field could also lead to immediate improvements in data quality.

\section{Option 3 -Demographic surveillance sites and special research} studies

Demographic surveillance sites (DSS), in which the vital events and background characteristics associated with all residents are recorded prospectively, should be an important data source on early pregnancy loss, stillbirths, and preterm births. INDEPTH, a network of researchers from DSS around the world, promotes the registration of pregnancy and pregnancy outcomes as a means of early registration of births but also for identifying stillbirths and abortions [73]. Although the collection of pregnancy loss data is highly recommended in DSS, it is unclear how many current DSS actually collect pregnancy loss data, and among those that do, how many regularly or ever report such results. Few DSS data could be located in the published or web-based literature. In contrast, the DSS in Matlab, Bangladesh, includes stillbirth data in their routine reporting [65]. The evaluation of existing but publicly unavailable data on late pregnancy loss from demographic surveillance sites demands immediate attention and could potentially offer important clues to improved data collection.

\section{Improving stillbirth cause-of-death data}

While lack of data on stillbirth cause-of-death is a large hurdle to overcome, another major barrier is the lack of a classification system that is feasible for low-income countries and which is based on categories that can be mapped alongside more complex classifications which are useful in high-income settings [49]. Currently, twothirds of the world's stillbirths lack programmatically meaningful cause-of-death categories which could be used to inform prevention strategies.

Stillbirth classification systems have proliferated over the years and a review suggests at least 33 are in use [54]. Most of these are designed for high-income countries and involve laboratory and pathological examination of the baby and the placenta, so are impractical for use when the only information for most stillbirths is through verbal autopsy occurring a year or even longer after the loss. International consensus for standard classification and comparable attribution of cause are essential to improve the comparability and use of stillbirth cause-ofdeath data. This can only be achieved if the classification 
system is practically applicable and serves the needs of high-as well as low-mortality settings.

High-mortality settings require broad causal categories which can be distinguished through simple clinical observations or even through verbal autopsy and which are programmatically relevant in that they identify conditions associated with large numbers of deaths. One useful distinction for stillbirth prevention strategies is between macerated (antepartum) and fresh (intrapartum) stillbirths. Rates of fresh stillbirths are assumed to reflect the quality of intrapartum care (care in labor), while rates of macerated stillbirths are assumed to reflect the quality of fetal growth and of care during the antenatal period. The antepartum/intrapartum distinction can generally be explored in verbal autopsy studies with questions pertaining to the appearance of the infant's skin. Such questions have been used and are believed to be well understood by respondents, though they have not yet been systematically validated. There is some potential for misclassification between these categories. For example, in settings with major delays in access to health care, stillbirths may die during labor, but not be delivered for days by which time they are classified as macerated. Conversely, some intrapartum stillbirths may be due to infections or congenital causes. Also, women who have delivered stillbirths may not be shown the infant, and therefore could not adequately respond to questions about the infant's appearance. The extent of this misclassification may vary locally and requires further research [56].

Once these two major categories (antepartum and intrapartum) are defined, a more detailed set of programmatically relevant causal groups can be distinguished. This intermediate level of detail is possible with clinical data and achievable in most facility deaths in LMICs (e.g., the South African National Saving Babies data) [74, 75]. For high-income countries, the existing complex classification systems often require sophisticated investigation but can be mapped onto simpler clinical categories (Figure 6). In verbal autopsy data and even in clinical assessment, some causal groups will be systematically underestimated. For example, congenital abnormalities are underestimated even in high-income countries but are markedly underestimated in verbal autopsy data because only obvious external abnormalities are detected and important internal structural and metabolic disorders are missed. Data from the literature show that around $5-15 \%$ of stillbirths are attributed to a congenital cause. Another important cause of stillbirth that is often missed is maternal syphilis. Figure 6 proposes groupings allowing a layered approach with increasing complexity of causal attribution in varying settings. Much could be learned by reclassifying existing data on stillbirth causes of death using the classification system proposed in Figure 6 (or some adaptation thereof) via collaboration with the original authors responsible for data collection. Such an exercise would quickly and inexpensively test this proposed classification and identify any caveats in the interpretation of the results.

Such a classification system for stillbirth cause-of-death would allow comparability between different data collection systems, such as verbal autopsy and more complex data systems (Figure 6). Several verbal autopsy tools now exist, thus gaining consensus on a standardized verbal autopsy tool would be an important advance. Such a tool would need to be tested in a wide variety of contexts. Data on avoidable factors contributing to stillbirths could also be addressed within the verbal autopsy questionnaire by adding a social autopsy module covering questions regarding care-seeking and beneficial or harmful traditional practices, for example. Much more in-depth information would be available through the use of a stillbirth audit, and there are a number of LMICs attempting to increase the coverage and quality of their audit networks. South Africa is an example of a country which has achieved both high coverage and high quality of perinatal audit data that are used for national decisionmaking [76].

\section{Conclusion}

Despite more than three million annual stillbirths and approximately one million neonatal deaths directly due to preterm birth, these burdens and the associated loss to families and nations are rarely highlighted in global health policy and research agendas. The impact of the combined numbers of deaths from stillbirth and preterm birth, plus the morbidity and long-term disability associated with preterm birth, is considerable. Clinical researchers and epidemiologists face formidable barriers in collecting and analyzing data about prevalence and interventions, particularly in South Asia and sub-Saharan Africa where two-thirds of these events occur. The places with the highest risk currently have the least information available. Yet, the quantity and quality of information could be improved, even in the short-term by: (1) seizing opportunities to add or test the measurement of stillbirths and preterm births to ongoing data collection mechanisms; (2) using consistent definitions and classification systems across current data collection mechanisms and research studies; and (3) improving global estimates for both outcomes. Research into etiologic mechanisms responsible for stillbirth and preterm birth has been hampered by the lack of standardized definitions and measurement protocols for assessing these outcomes. The global economic burdens related to these outcomes remain a significant research gap.

From this review, the priority gaps in existing estimates and in the data for effective program design include the following: 


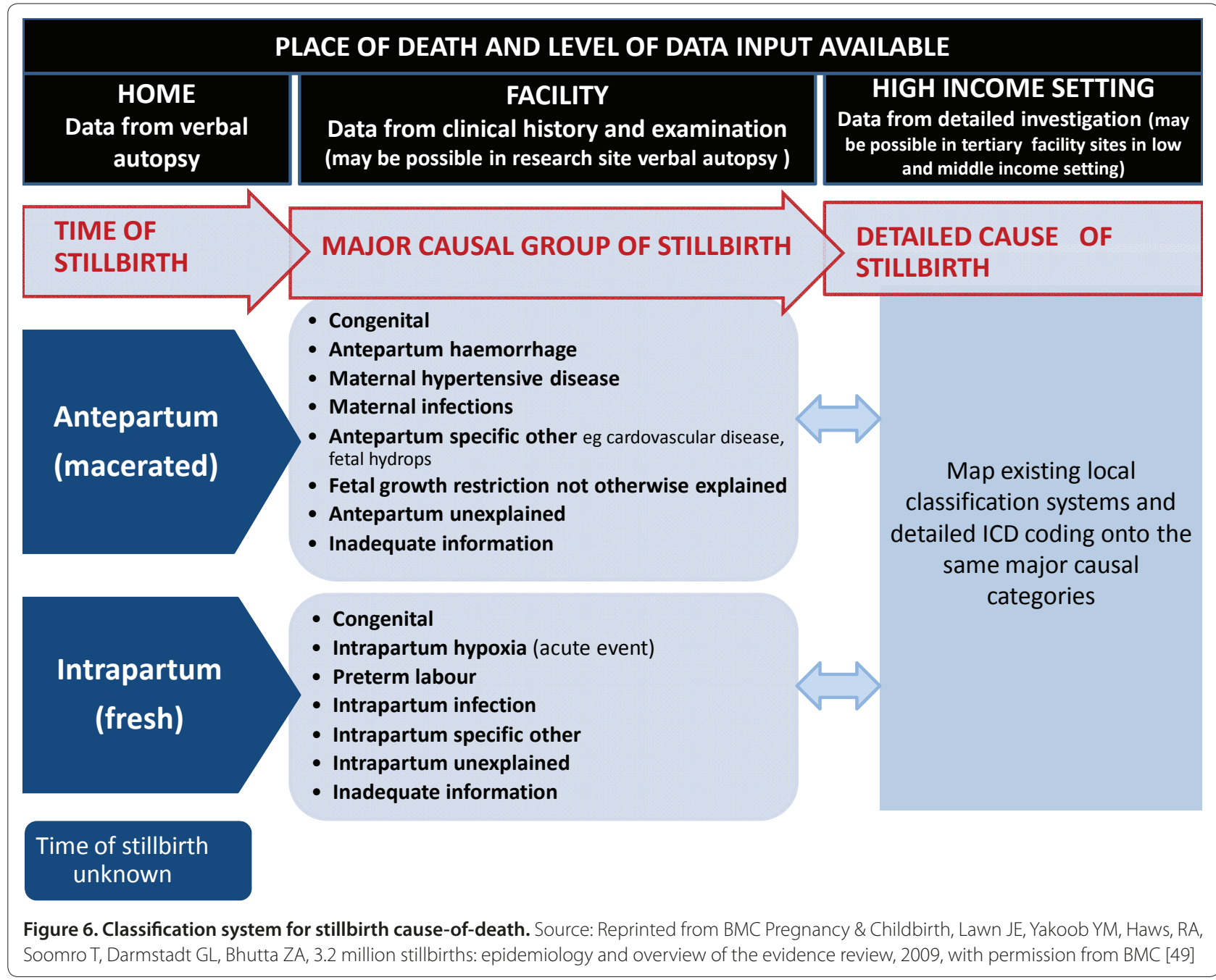

- Systematic estimates for causes of stillbirth are required to increase visibility and prioritize action to reduce these deaths. Agreement around a simplified classification system is a key step to underpin global estimates.

- The lack of systematic country-level estimates for the prevalence of preterm birth, based on well-defined and standard phenotype classification, is an important gap affecting the visibility of preterm birth globally. The lack of information for preterm prevalence is most marked in Africa and the Eastern Mediterranean. Virtually no consistent data on preterm prevalence trends are available from LMICs. The development of methods to permit reliable population-based data on trends in preterm birth in these countries is a key priority.

- New analysis is required to better define the risk of death at varying gestational ages, and to separate direct from indirect risks. Input data sets would need to include individual-level data on birth weight, gestational age, mortality outcome, and ideally, comparable causes of death.
- Acute morbidity and long-term sequelae of preterm birth remain virtually unstudied in LMICs, despite the fact that survival is now increasing in some of these settings. Tracking morbidity is crucial. Standard tools and protocols to assess morbidity and long- term sequelae across varying cultures are lacking. Attempts at these global estimates are severely hampered by the lack of data.

Opportunities highlighted by this review that could improve the availability and quality of data, even in the short term, include:

- Improve the capture and quality of pregnancy outcome data through household surveys, which is the main data source for the countries with $75 \%$ of the global burden, and undertake validation studies. The expanded number of demographic surveillance sites currently functioning in various LMICs offer excellent opportunities to compare prospective versus retrospective reporting on pregnancy outcomes. 
- Increase awareness of, and compliance with, standard definitions for stillbirth and preterm birth, and more frequently include stillbirth and gestational age data in existing data collection systems (vital registration, facility-based data and research studies). Current ICD 10 codes for both stillbirth and preterm birth need to be updated to reflect definitions currently in use and advances in understanding made in the last decade. A simplified classification system for stillbirth cause-ofdeath could also be incorporated into the ICD 11. This would allow data from a standardized verbal autopsy tool and other data collection systems in LMICs to improve input data for future global estimates.

- Expand and strengthen the coverage and quality of existing data collection mechanisms, especially vital registration, and facility data by instituting a standard death certificate for stillbirth and neonatal death linked to revised International Classification of Diseases coding.

- Validate a simple, standardized classification system for stillbirth cause-of-death that is feasible though verbal autopsy.

- Improve systems and tools to capture acute morbidity and long-term impairment outcomes following preterm birth and other adverse pregnancy or neonatal events.

In addition to these priority actions to improve preterm birth and stillbirth data in the immediate future, there is an extensive research agenda around the epidemiology of preterm births and stillbirths and many possible research questions too detailed to list here. The final article in this report presents a Global Action Agenda developed by global stakeholders at the GAPPS International Conference on Prematurity and Stillbirth held in May 2009, and includes short- and long-term objectives related to the epidemiology of preterm birth and stillbirth [16].

The numbers discussed in this report are large-on par with the issues considered the greatest priorities in global health today, and indeed larger than some that receive major attention, such as two million annual HIV/AIDS deaths. Yet, preterm birth and particularly stillbirth are not included amongst global priorities. This invisibility is partly an issue of data, but remains a reality despite increasing quality and progress for global estimates. Another critical issue is the value put on a baby's life-a newborn baby remains the most vulnerable human and a preterm newborn is even more vulnerable.

Each of these losses is a bereavement for families and may leave a deeper scar than a death which is openly acknowledged and mourned. Long-term follow-up studies show that 20 years after a stillbirth, a woman may remain in a delayed grief response $[77,78]$. The societies where stillbirth and preterm birth have become priorities are those where such babies are expected to live, and women and families can express their loss. Indeed, the power of these families to use data for change may be likened to the power of individuals who lost loved ones from HIV/AIDS and advocated successfully for change. Data alone will not result in change until society and leaders recognize that these deaths are a loss that can and must count and be prevented.

\section{Acknowledgements}

This report was supported by the Global Alliance to Prevent Prematurity and Stillbirth, an initiative of Seattle Children's, through a grant from the Bill \& Melinda Gates Foundation. JEL is funded by Saving Newborn Lives/Save the Children through a grant from the Bill \& Melinda Gates Foundation. We thank Catherine Waszak for excellent administrative support.

This article has been published as part of BMC Pregnancy and Childbirth Volume 10 Supplement 1, 2010. The full contents of this report are available online at http://www.biomedcentral.com/1471-2393/10?issue=S1. We thank all members of the GAPPS Review Group for their contributions and review of the seven articles in this report, and list them here in alphabetical order: Fernando C Barros, Maneesh Batra, Zulfiqar Ahmed Bhutta, Anne-Véronique Fajon, Michael G Gravett, Thomas N Hansen, Maureen Kelley, Joy E Lawn, Toni M Nunes, Craig E Rubens, Megan Sather, Cynthia Stanton, Cesar G Victora, and Rachel Zaentz

Additional File

Additional file 1 shows relevant definitions

\section{Author details}

'Saving Newborn Lives/Save the Children, 11 South Way, Pinelands Cape Town, South Africa

2Department of Obstetrics and Gynecology, University of Washington, Seattle, Washington USA

${ }^{3}$ Global Alliance to Prevent Prematurity and Stillbirth, an initiative of Seattle Children's, Seattle, Washington, USA

${ }^{4}$ Department of Pediatrics at University of Washington School of Medicine, Seattle, Washington, USA

${ }^{5}$ Department of Population, Family and Reproductive Health, The Johns Hopkins Bloomberg School of Public Health, Baltimore, Maryland, USA

\section{Authors' contributions}

The article was written by JEL and CS and reviewed by MG, CR, TN and the GAPPS Review Group.

\section{Competing interests}

The authors declare that they have no competing interests.

Published: 23 February 2010

\section{References}

1. Lawn JE, Kerber K, Enweronu-Laryea C, Massee Bateman O: Newborn survival in low resource settings--are we delivering? BJOG 2009, 116 Suppl 1:49-59.

2. Lawn JE, Cousens S, Zupan J: 4 million neonatal deaths: when? Where? Why? Lancet 2005, 365(9462):891-900.

3. Lawn JE, Cousens SN, Darmstadt GL, Bhutta ZA, Martines J, Paul V, Knippenberg R, Fogstad H: 1 year after The Lancet Neonatal Survival Series-was the call for action heard? Lancet 2006, 367(9521):1541-1547.

4. Lawn JE, Wilczynska-Ketende K, Cousens SN: Estimating the causes of 4 million neonatal deaths in the year 2000. Int J Epidemiol 2006, 35(3):706-718.

5. Darmstadt GL, Bhutta ZA, Cousens S, Adam T, Walker N, de Bernis L: Evidence-based, cost-effective interventions: how many newborn babies can we save? Lancet 2005, 365(9463):977-988.

6. Behrman RE, Butler AS, Institute of Medicine, Committee on Understanding Premature Birth and Assuring Healthy Outcomes: Preterm Birth: Causes, Consequences, and Prevention. The National Academies Press 2007.

7. Stanton C, Lawn JE, Rahman H, Wilczynska-Ketende K, Hill K: Stillbirth rates: delivering estimates in 190 countries. Lancet 2006, 367(9521):1487-1494.

8. Jamison D, Shahid-Salles S, Jamison J, et al.: Incorporating Deaths near the Time of Birth into Estimates of the Global Burden of Disease. In Global 
Burden of Disease and Risk Factors. 2nd edition. Edited by Lopez AM, C; Ezzati $M$ et al. Washington DC: The World Bank and Oxford University Press; 2006.

9. End Poverty 2015: Millennium Development Goals [http://www.un.org/ millenniumgoals]

10. McClure EM, Goldenberg RL, Bann CM: Maternal mortality, stillbirth and measures of obstetric care in developing and developed countries. Int $\mathrm{J}$ Gynaecol Obstet 2007, 96(2):139-146.

11. Gravett MG, Rubens CE, Nunes TM, and GAPPS Review Group: Global report on preterm birth and stillbirth (2 of 7): discovery science. BMC Pregnancy and Childbirth 2010, 10 (Suppl 1):S2.

12. Barros FC, Bhutta ZA, Batra M, Hansen TN, Victora CG, Rubens CE, and GAPPS Review Group: Global report on preterm birth and stillbirth (3 of 7): evidence for effectiveness of interventions BMC Pregnancy and Childbirth 2010, 10 Suppl 1:S3.

13. Victora CG, Rubens $C E$, and the GAPPS Review Group: Global report on preterm birth and stillbirth (4 of 7): delivery of interventions. BMC Pregnancy and Childbirth 2010, 10 (Suppl 1):S4.

14. Sather M, Fajon AV, Zaentz R, Rubens CE, and the GAPPS Review Group: Global report on preterm birth and stillbirth (5 of 7): advocacy barriers and opportunities. BMC Pregnancy and Childbirth 2010, 10 Suppl 1:S5.

15. Kelley MK, Rubens CE, and the GAPPS Review Group: Global report on preterm birth and stillbirth (6 of 7): ethical considerations BMC Pregnancy and Childbirth 2010, 10 (Suppl 1):S6.

16. Rubens CE, Gravett MG, Victora CG, Nunes TM, and the GAPPS Review Group: Global report on preterm birth and stillbirth (7 of 7): mobilizing resources to accelerate innovative interventions BMC Pregnancy and Childbirth 2010, 10 (Suppl 1):S7.

17. Lawn J: 4 million neonatal deaths: An analysis of available cause-of-death data and systematic country estimates with a focus on "birth asphyxia". [A PhD Thesis]. University College London; 2008.

18. GRADE Working Group: Grading quality of evidence and strength of recommendations. BMJ 2008, 328.

19. Joseph KS, Kramer MS, Marcoux S, Ohlsson A, Wen SW, Allen A, Platt R: Determinants of preterm birth rates in Canada from 1981 through 1983 and from 1992 through 1994. NEngl J Med 1998, 339(20):1434-1439.

20. Joseph KS, Demissie K, Kramer MS: Obstetric intervention, stillbirth, and preterm birth. Semin Perinatol 2002, 26(4):250-259.

21. Beck S, Wojdyla D, Say L, Pilar Betran A, Merialdi M, Harris Requejo J, Rubens C, Menon R, Van Look P: The worldwide incidence of preterm birth: a systematic review of maternal mortality and morbidity. Bull World Health Organ 2010, 88(1):1-80.

22. UNICEF: Low birth weight: Country, regional and global estimates. New York: United Nations Children's Fund; 2004.

23. Blanc AK, Wardlaw T: Monitoring low birth weight: an evaluation of international estimates and an updated estimation procedure. Bull World Health Organ 2005, 83(3):178-185.

24. Steer P: The epidemiology of preterm labor--a global perspective. $J$ Perinat Med 2005, 33(4):273-276.

25. Steer P: The epidemiology of preterm labour. BJOG 2005, 112 Suppl 1:1-3.

26. Martin JA, Hamilton BE, Sutton PD, Ventura SJ, Menacker F, Kirmeyer S, Munson ML: Births: final data for 2005. Natl Vital Stat Rep 2007, 56(6):1-103.

27. Statistics NCFH: Health, United States 2007 With Chartbook on Trends in the Health of Americans. Edited by U.S. Department of Health and Human Services CfDCaP. Hyattsville, MD: U.S. Government Printing Office; 2007:Table 19 Infant, Neonatal, Postneonatal.

28. Wong E: Health of Native Hawaiians and Other Pacific Islanders in King County. Public Health Data Watch 2008, PH-SK, ed.10

29. McCarthy BJ, Terry J, Rochat RW, Quave S, Tyler CW, Jr.: The underregistration of neonatal deaths: Georgia 1974--77. Am J Public Health 1980, 70(9):977-982.

30. Phelan ST, Goldenberg R, Alexander G, Cliver SP: Perinatal mortality and its relationship to the reporting of low-birthweight infants. Am J Public Health 1998, 88(8):1236-1239.

31. Yasmin S, Osrin D, Paul E, Costello A: Neonatal mortality of low-birth-weight infants in Bangladesh. Bull World Health Organ 2001, 79(7):608-614

32. Costeloe K, Hennessy E, Gibson AT, Marlow N, Wilkinson AR: The EPICure study: outcomes to discharge from hospital for infants born at the threshold of viability. Pediatrics 2000, 106(4):659-671.

33. Wood NS CK, Gibson AT, Hennessy EM, Marlow N, Wilkinson AR: The EPICure study: growth and associated problems in children born at 25 weeks of gestational age or less. . Arch Dis Child Fetal Neonatal Ed 2003,
88(6):F492-F500

34. Critical care decisions in fetal and neonatal medicine: ethical issues. Nuffield Council on Bioethics 2006

35. WHO: Maternal anthropometry and pregnancy outcomes: a WHO collaborative study. Geneva: World Health Organization; 1995.

36. Goldenberg RL, Culhane JF, lams JD, Romero R: Epidemiology and causes of preterm birth Lancet 2008, 371(9606):75-84

37. Ananth $\mathrm{CJ}, \mathrm{KS} ;$ Oyelese, $Y$; et al.: Trends in preterm birth and perinatal mortality among singletons: United States, 1989 through 2000. Obstetrics and Gynecology 2005, 105(5 Pt 1):1084-1091.

38. Silveira MF, Santos IS, Barros AJ, Matijasevich A, Barros FC, Victora CG: Increase in preterm births in Brazil: review of population-based studies. Rev Saude Publica 2008, 42(5):957-964.

39. Barros FC, Velez Mdel P: Temporal trends of preterm birth subtypes and neonatal outcomes. Obstet Gynecol 2006, 107(5):1035-1041.

40. WHO: The World Health Report 2005: make every mother and child count Geneva: World Health Organization; 2005.

41. Lawn JZ, J; Begkoyian, G; et al.: Newborn Survival, 2nd edition. Washington DC The World Bank and the National Institutes of Health; 2005.

42. Barros FC, Huttly SR, Victora CG, Kirkwood BR, Vaughan JP: Comparison of the causes and consequences of prematurity and intrauterine growth retardation: a longitudinal study in southern Brazil. Pediatrics 1992, 90(2 Pt 1):238-244.

43. Tomashek KM, Shapiro-Mendoza CK, Davidoff MJ, Petrini JR: Differences in mortality between late-preterm and term singleton infants in the United States, 1995-2002. J Pediatr 2007, 151(5):450-456, 456 e451.

44. Draper EZ, J; Field, DJ; et al.: Mortality patterns among very preterm babies: a comparative analysis of two European regions in France and England. Arch Dis Child Fetal Neonatal Ed 2007, 92 (5):F356-360

45. Wood NS, Marlow N, Costeloe K, Gibson AT, Wilkinson AR: Neurologic and developmental disability after extremely preterm birth. EPICure Study Group. N Eng/ J Med 2000, 343(6):378-384.

46. Chan K, Ohlsson A, Synnes A, Lee DS, Chien LY, Lee SK: Survival, morbidity, and resource use of infants of 25 weeks' gestational age or less. Am J Obstet Gynecol 2001, 185(1):220-226.

47. Dammann O, Leviton A, Gappa M, Dammann CE: Lung and brain damage in preterm newborns, and their association with gestational age, prematurity subgroup, infection/inflammation and long term outcome. BJOG 2005, 112 Suppl 1:4-9.

48. WHO: International Classification of Diseases and Related Health Problems, 10th Revision. Volume 2. Geneva; 1993

49. Lawn JE, Yakoob MY, Haws RA, Soomro T, Darmstadt GL, Bhutta ZA: 3.2 million stillbirths: epidemiology and overview of the evidence review. BMC Pregnancy Childbirth 2009, 9 (Suppl 1):S2

50. WHO: Perinatal and neonatal mortality for the year 2000: Country, regional and global estimates. Geneva: World Health Organization; 2006.

51. Conde-Agudelo A, Rosas-Bermudez A, Kafury-Goeta AC: Birth spacing and risk of adverse perinatal outcomes: a meta-analysis. JAMA 2006, 295(15):1809-1823

52. Pattison R: Saving Babies 2001: 2nd Perinatal Care Survey of South Africa. 2004.

53. Pattison RS, L, Makin, JD; et al.: Critical incident audit and feedback to improve perinatal and maternal mortality and morbidity. Cochrane Database Systematic Review 2005, 19(4):CD002961.

54. Korteweg FJ, Gordijn SJ, Timmer A, Erwich JJ, Bergman KA, Bouman K, Ravise $J M$, Heringa MP, Holm JP: The Tulip classification of perinatal mortality: introduction and multidisciplinary inter-rater agreement. BJOG 2006, 113(4):393-401.

55. Gardosi J, Kady SM, McGeown P, Francis A, Tonks A: Classification of stillbirth by relevant condition at death (ReCoDe): population based cohort study. BMJ 2005, 331(7525):1113-1117

56. Lawn J, Shibuya K, Stein C: No cry at birth: global estimates of intrapartum stillbirths and intrapartum-related neonatal deaths. Bull World Health Organ 2005, 83(6):409-417.

57. De Muylder X: Perinatal mortality audit in a Zimbabwean district. Paediatr Perinat Epidemio/ 1989, 3(3):284-293.

58. Wilkinson D: Perinatal mortality--an intervention study. S Afr Med J 1991, 79(9):552-553.

59. Bugalho A, Bergstrom S: Value of perinatal audit in obstetric care in the developing world: a ten-year experience of the Maputo model. Gynecol Obstet Invest 1993, 36(4):239-243. 
60. Wilkinson D: Avoidable perinatal deaths in a rural hospital: strategies to improve quality of care. Trop Doct 1995, 25(1):16-20.

61. Lawn JE, Osrin D, Adler A, Cousens S: Four million neonatal deaths: counting and attribution of cause of death. Paediatr Perinat Epidemio/ 2008 , 22(5):410-416.

62. Lawn JE MB, Ross SR. : The Healthy Newborn: A reference guide for program managers. Atlanta; 2001.

63. Parker J, Stanton C, Lawn J: A systematic review of methods for gestational age assessment. Baltimore, Maryland; 2008.

64. DHS StatCompiler [www.measuredhs.com]

65. International Centre for Diarrheal Disease Research B: Registration of Health and Demographic Events 2000; Health and Demographic Surveillance System, Matlab. Dhaka: International Centre for Diarrheal Disease Research, Bangladesh; 2002

66. Casterline JB: Collecting data on pregnancy loss: a review of evidence from the World Fertility Survey. Stud Fam Plann 1989, 20(2):81-95.

67. Garenne M: Do women forget their births? A study of maternity histories in a rural area of Senegal (Niakhar). United Nations Population Bulletin 1994, 36:43-54

68. Goldman NM, L; Westoff; C:: Peru Experimental Study. Calverton, Maryland; 1989.

69. Westoff CM, L; Goldman, N:: Dominican Republic Experimental Study; An evaluation of fertility and child health information. Columbia, Maryland: Institute for Resource Development/Macro Systems; 1990.

70. Becker S, Sosa D: An experiment using a month-by-month calendar in a family planning survey in Costa Rica. Studies in Family Planning 1992, 23(6 (Pt 1)):386-391.

71. Stanton C: Perinatal mortality in the Philippines: an investigation into the use of demographic survey data for the study of perinatal mortality and its determinants. [A PhD Thesis]. The Johns Hopkins University School of Hygiene and Public Health, Department of Population Dynamics; 1996.

72. Espeut D: A validation of birth and pregnancy histories in Matlab, Bangladesh; Dissertation. Baltimore, Maryland: Department of Population, Family and Reproductive Health Sciences, The Johns Hopkins School of Hygiene and Public Health; 2002

73. InDepth [www.indepth-network.org]

74. The Child Healthcare Problem Identification Programme [http://www. childpip.org.za/]

75. The Child Healthcare Problem Identification Programme - Saving Children reports [http://www.childpip.org.za/index.php?option=com_content\&task= view\&id=16\&ltemid=30]

76. Bradshaw D, Chopra M, Kerber K, Lawn JE, Bamford L, Moodley J, Pattinson R, Patrick M, Stephen C, Velaphi S: Every death counts: use of mortality audit data for decision making to save the lives of mothers, babies, and children in South Africa. Lancet 2008, 371(9620):1294-1304.

77. Leon IG: Psychodynamics of perinatal loss. Psychiatry 1986, 49(4):312-324.

78. Schapp A, Wolf, H, Bruinse, HW, et al. : Long term impact of perinatal bereavement: comparison of grief reactions after intrauterine loss versus neonatal death. Eur J Obstet Gynecol Reprod Biol 1997, 75:161-167.

79. Password F: Spontaneous preterm birth of liveborn infants in women at low risk in Australia over 10 years: a population-based study. BJOG: An International Journal of Obstetrics and Gynecology 2007, 114(6):731-735.

80. Olsen P, Laara E, Rantakallio P, Jarvelin MR, Sarpola A, Hartikainen AL: Epidemiology of preterm delivery in two birth cohorts with an interval of 20 years. Am J Epidemiol 1995, 142(11):1184-1193.

81. Breart G, Blondel B, Tuppin P, Grandjean H, Kaminski M: Did preterm deliveries continue to decrease in France in the 1980s? Paediatr Perinat Epidemiol 1995, 9(3):296-306.

82. Davidson SL, A; Peleg, D; et al.: Are babies getting bigger? Secular trends in fetal growth in Israel - a retrospective hospital-based cohort study. Israeli Medical Association 2007, 9(9):649-651.

83. Takimoto H, Yokoyama T, Yoshiike N, Fukuoka H: Increase in low-birth-weight infants in Japan and associated risk factors, 1980-2000. J Obstet Gynaecol
Res 2005, 31(4):314-322

84. Mantell CD, Craig ED, Stewart AW, Ekeroma AJ, Mitchell EA: Ethnicity and birth outcome: New Zealand trends 1980-2001: Part 2. Pregnancy outcomes for Maori women. Aust N Z J Obstet Gynaecol 2004, 44(6):537-540.

85. Gray R, Bonellie SR, Chalmers J, Greer I, Jarvis S, Williams C: Social inequalities in preterm birth in Scotland 1980-2003: findings from an area-based measure of deprivation. BJOG 2008, 115(1):82-90

86. NationalCollaboratingCentreforWomen'sandChildren'sHealth: Antenatal care. Routine care for the healthy pregnant woman. London: National Institute for Clinical Excellence - NICE; 2003

87. Hamilton BE, Minino AM, Martin JA, Kochanek KD, Strobino DM, Guyer B: Annual summary of vital statistics: 2005. Pediatrics 2007, 119(2):345-360.

88. Morken NH, Kallen K, Hagberg H, Jacobsson B: Preterm birth in Sweden 1973-2001: rate, subgroups, and effect of changing patterns in multiple births, maternal age, and smoking. Acta Obstet Gynecol Scand 2005, 84(6):558-565.

89. Barros F, Victora, C, Matijasevich, A, et al.: Preterm births, low birthweight and intra-uterine growth restriction in three birth cohorts in southern Brazil; 1982, 1993, and 2004. Cad Saude Pub/ 2007, in press.

90. Silva AA, Barbieri MA, Gomes UA, Bettiol H: Trends in low birth weight: a comparison of two birth cohorts separated by a 15-year interval in Ribeirao Preto, Brazil. Bull World Health Organ 1998, 76(1):73-84.

91. Gonzalez R, Merialdi M, Lincetto O, Lauer J, Becerra C, Castro R, Garcia P, Saugstad OD, Villar J: Reduction in neonatal mortality in Chile between 1990 and 2000. Pediatrics 2006, 117(5):e949-954.

92. Lin LL, Y; Zhang, $X$; et al.: Sampling survey on low birthweight in China in 1998. Zhonghua Yu Fang Yi Xue Za Zhi 2002, 36(3):149-153.

93. Joesoef MR, Hillier SL, Wiknjosastro G, Sumampouw H, Linnan M, Norojono W, Idajadi A, Utomo B: Intravaginal clindamycin treatment for bacterial vaginosis: effects on preterm delivery and low birth weight. Am J Obstet Gynecol 1995, 173(5):1527-1531.

94. Mamun AA, Padmadas SS, Khatun M: Maternal health during pregnancy and perinatal mortality in Bangladesh: evidence from a large-scale community-based clinical trial. Paediatr Perinat Epidemio/ 2006, 20(6):482-490

95. Mahomed K, Bhutta Z, Middleton P: Zinc supplementation for improving pregnancy and infant outcome. Cochrane Database Syst Rev 2007(2):CD000230

96. Rayco-Solon P, Fulford AJ, Prentice AM: Differential effects of seasonality on preterm birth and intrauterine growth restriction in rural Africans. Am J Clin Nutr 2005, 81(1):134-139.

97. Christian P, Khatry SK, Katz J, Pradhan EK, LeClerq SC, Shrestha SR, Adhikari RK, Sommer A, West KP, Jr.: Effects of alternative maternal micronutrient supplements on low birth weight in rural Nepal: double blind randomised community trial. BMJ 2003, 326(7389):571.

98. Parveen Z: Birthweight percentiles by gestational age: a hospital-based study. J Ayub Med Coll Abbottabad 2001, 13(2):2-27.

99. Lone F, Qureshi R, Emmanuel F: Maternal anaemia and its impact on perinatal outcome in a tertiary care hospital in Pakistan. Eastern Mediterranean Health Journal 2004, 10(6):801-807.

100. Kuti O, Owa JA: Gestational age-specific neonatal mortality among preterm singleton births in a Nigerian tertiary institution. Int J Gynaecol Obstet 2003, 80(3):319-320.

101. Magowan BA, Bain M, Juszczak E, Mclnneny K: Neonatal mortality amongst Scottish preterm singleton births (1985-1994). Br J Obstet Gynaecol 1998, 105(9):1005-1010.

doi:10.1186/1471-2393-S1-S

Cite this article as: Lawn JE, et al: Global report on preterm birth and stillbirth (1 of 7): definitions, description of the burden and opportunities to improve data. BMC Pregnancy and Childbirth 2010, 10(Suppl 1):S1 